Article

\title{
Diversity of Pharmacological Properties in Chinese and European Medicinal Plants: Cytotoxicity, Antiviral and Antitrypanosomal Screening of 82 Herbal Drugs
}

Florian Herrmann ${ }^{1}$, Marta R. Romero ${ }^{2}$, Alba G. Blazquez ${ }^{2}$, Dorothea Kaufmann ${ }^{1}$, Mohamed L. Ashour ${ }^{3}$, Stefan Kahl ${ }^{4}$, Jose J.G. Marin ${ }^{2}$, Thomas Efferth ${ }^{5}$ and Michael Wink ${ }^{1, *}$

1 Institute of Pharmacy and Molecular Biotechnology, Heidelberg University, Heidelberg 69120, Germany; E-Mails: Florian.Herrmann@t-online.de (F.H.); D.Kaufmann@uni-heidelberg.de (D.K.)

2 Laboratory of Experimental Hepatology and Drug Targeting (HEVEFARM), National Institute for the Study of Liver and Gastrointestinal Diseases (CIBERehd), University of Salamanca, Salamanca 37007, Spain; E-Mails: marta.rodriguez@ciberehd.org (M.R.R.); albamgb@usal.es (A.G.B.); jjgmarin@usal.es (J.J.G.M.)

3 Department of Pharmacognosy, Faculty of Pharmacy, Ain Shams University, Abbassia, Cairo 11566, Egypt; E-Mail: Mohamed_ashour@pharm.asu.edu.eg (M.L.A.)

4 Isostatic Products, RHI AG, Leoben 8700, Austria; E-Mail: Stefan.kahl@gmail.com

5 Department of Pharmaceutical Biology, Institute of Pharmacy and Biochemistry, University of Mainz, Mainz 55128, Germany; E-Mail: efferth@uni-mainz.de

* Author to whom correspondence should be addressed; E-Mail: wink@uni-hd.de; Tel.: +49-6221-54-4880; Fax: +49-6221-54-4884.

Received: 29 July 2011; in revised form: 5 August 2011/ Accepted: 15 September 2011/ Published: 26 September 2011

Abstract: In an extensive screening, the antiviral, antitrypanosomal and anticancer properties of extracts from 82 plants used in traditional Chinese medicine and European phytomedicine were determined. Several promising plants that were highly effective against hepatitis B virus (HBV), bovine viral diarrhoea virus (BVDV) - a flavivirus used here as a surrogate in vitro model of hepatitis $\mathrm{C}$ virus, trypanosomes (Trypanosoma brucei brucei) and several cancer cell lines were identified. Six aqueous extracts from Celosia cristata, Ophioglossum vulgatum, Houttuynia cordata, Selaginella tamariscina, Alpinia galanga and Alpinia oxyphylla showed significant antiviral effects against BVDV without toxic effects on host embryonic bovine trachea (EBTr) cells, while Evodia lepta, Hedyotis 
diffusa and Glycyrrhiza spp. demonstrated promising activities against the HBV without toxic effects on host human hepatoblastoma cells transfected with HBV-DNA (HepG2 2.2.15) cells. Seven organic extracts from Alpinia oxyphylla, Coptis chinensis, Kadsura longipedunculata, Arctium lappa, Panax ginseng, Panax notoginseng and Saposhnikovia divaricata inhibited T. b. brucei. Moreover, among fifteen water extracts that combined high antiproliferative activity $\left(\mathrm{IC}_{50} 0.5-20 \mu \mathrm{g} / \mathrm{mL}\right)$ and low acute in vitro toxicity $\left(0-10 \%\right.$ reduction in cell viability at $\left.\mathrm{IC}_{50}\right)$, Coptis chinensis presented the best beneficial characteristics. In conclusion, traditional herbal medicine from Europe and China still has a potential for new therapeutic targets and therapeutic applications.

Keywords: anticancer drugs; gastrointestinal tumors; traditional Chinese medicine; cytotoxicity; hepatitis B; hepatitis C; HepG2 2.2.15; BVDV; Trypanosoma brucei brucei

\section{Introduction}

Traditional Chinese medicine (TCM) has a long history starting with the Shang Dynasty around $1500 \mathrm{BC}$ and officially uses approximately 4773 herbs, while the number of locally used plants is probably much higher [1]. Clinical efficacy was shown in various examples, one of the best known is that of artemisinin from Artemisia annua, commonly used against malaria, but also effective against T. b. brucei, viral infections and cancer [2-8].

European medicine also has a long tradition of at least 2500 years with the two important early scholars Hippocrates and Dioscorides who described more than 400 medicinal plants 2000 years ago, many of which are still in use today [9]. Many pure therapeutic agents used in modern medicine were originally based on herbal medicine; in fact, the process of developing new drugs from European herbal medicine is still alive and important discoveries are regularly made [10,11]. Even though the theoretical concept of traditional medicine differs between Europe and China, often the same plants were and are still used in both cultures to treat the same or similar health disorders. Modern European phytotherapy also includes important herbal medicines from Africa and America.

Even though the diversity of plants and possible natural products is vast, the number of targets is usually limited (Table 1). Most natural products target proteins, biomembranes or DNA unselectively. Selective interaction is often the case when especially alkaloids mimic signal molecules and interact with receptors or enzymes. It is often possible to conclude from the type of the natural products to their most likely mode of action. Saponins and monoterpenes are active on the biomembrane, while polyphenols usually interact with proteins. Alkaloids also interact with proteins or the DNA.

The formations of covalent and of non-covalent bonds are the two modes of action that form the basis of all interactions between proteins and natural products.

The two main targets for the formation of covalent bonds are free amino and free SH groups. Aldehydes, isothiocyanates and epoxids can form covalent bonds with free amino groups while sesquiterpene lactones, disulfides (e.g., allicin), polyacetylenes and epoxides can form covalent bonds with free $\mathrm{SH}$ groups. 
Table 1. Targets in animal cells, bacteria cells and viruses [12].

\begin{tabular}{lll}
\hline Target & Activity & Secondary metabolites \\
\hline Biomembrane & Membrane disruption & Saponins \\
& $\begin{array}{l}\text { Disturbance of } \\
\text { membrane fluidity } \\
\text { Disturbance of membrane } \\
\text { proteins }\end{array}$ & Saponins, monoterpenes \\
& Monoterpenes \\
\hline
\end{tabular}

\section{Proteins}

(unspecific interaction)

Non-covalent bonding (change of $3 \mathrm{D}$ protein conformation)

Covalent bonding (change of $3 \mathrm{D}$ protein conformation)
Phenolic molecules (flavonoids, catechins, tannins, anthraquinones, quinones, lignans, phenylpropanoids)

Allicin, furanocoumarins, isothiocyanates, sesquiterpene lactones, aldehydes, epoxids, triple bonds

\section{Proteins}

(specific interaction)

Inhibition of enzymes

Inhibition of $\mathrm{Na}^{+} \mathrm{K}^{+}$pumps

Inhibition of microtubule

formation

Inhibition of protein

biosynthesis

Inhibition of transporters

Modulation of hormone

receptors

Modulation of ion channels

Modulation of neuroreceptors

Modulation of regulatory

proteins

Modulation of transcription

factors

DNA/RNA

Covalent modification

(alkylation)

Inhibition of DNA

topoisomerase I

Inhibition of transcription

Intercalation
Structural mimetics of signal molecules (many alkaloids, e.g., nicotine), hydrogen cyanide from cyanogens

Cardiac glycosides

Colchicine, podophyllotoxin, taxol,

vinblastine

Emetine, lectins

Non-protein amino acids

Isoflavonoids

Many alkaloids, aconitine

Many alkaloids, some non-protein amino acids

Caffeine, phorbol esters

Structural mimetics of hormones (e.g., isoflavones genistein, daidzein)

Aristolochic acids, furanocoumarins, pyrrolizidine alkaloids, molecules with epoxy groups

Berberine, camptothecin

Amanitine

Planar, aromatic and lipophilic molecules (anthraquinones, berberine, emetine, quinine, sanguinarine, furanocoumarins) 
The second mechanism of maybe even greater importance due to its universality is the formation of non-covalent bonds between phenolic OH-groups and amino groups. The proton of the phenolic OH-group can partly dissociate under physiological conditions so that unspecific interactions by forming strong, ionic bonds occur with proteins. Tannins are especially effective due to their large number of hydroxyl groups.

All of these interactions will change the three dimensional structure of the protein and thus inactivate it. The omnipresence of these unspecific natural products in plants explains the efficacy of many plant extracts. They are responsible for the great number of "hits" usually occurring in extended screenings of medicinal plant extracts (Table 2).

Table 2. Main Compounds of Plants used in this study $[9,13]$.

\begin{tabular}{|c|c|c|}
\hline Family & Species & Main Compounds \\
\hline Acanthaceae & Andrographis paniculata & Diterpenelactones \\
\hline Amaranthaceae & Celosia cristata & $\begin{array}{l}\text { Lectins (amarathin, isoamaranthin, celosianin), ferulic } \\
\text { acid }\end{array}$ \\
\hline \multirow[t]{5}{*}{ Apiaceae } & Bupleurum chinense & $\begin{array}{l}\text { Flavonoids (quercetin, rutin, isoquercetin, isorhamnetin), } \\
\beta \text {-sitosterol, } \beta \text {-sitosterol-3- } O \text {-glucosid, } \alpha \text {-spinasterol, } \\
\alpha \text {-spinasterol-3- } O \text {-glucoside }\end{array}$ \\
\hline & Bupleurum marginatum & $\begin{array}{l}\text { Flavonoids (quercetin, rutin, isoquercetin, isorhamnetin), } \\
\beta \text {-sitosterol, } \\
\beta \text {-sitosterol-3-O-glucosid, } \alpha \text {-spinasterol, } \\
\alpha \text {-spinasterol-3-O-glucoside }\end{array}$ \\
\hline & Centella asiatica & $\begin{array}{l}\text { Triterpenes (asiaticoside, asiatic acid, madecassic acid), } \\
\text { flavonoids (kaempferol), monoterpenes (camphor), fatty } \\
\text { acids (palmitic acid) }\end{array}$ \\
\hline & Cnidium monnieri & Monoterpenes (pinene), cnidium lactone \\
\hline & Saposhnikovia divaricata & Polyacetylenes, furanocoumarins, chromones \\
\hline \multirow[t]{4}{*}{ Araliaceae } & Eleutherococcus senticosus & $\begin{array}{l}\text { Saponins (ginsenosides), polyacetylenes, fatty acids, } \\
\text { amino acids, polysaccharides }\end{array}$ \\
\hline & Panax ginseng China & $\begin{array}{l}\text { Saponins (ginsenosides } \mathrm{Rb}_{1}, \mathrm{Rb}_{2}, \mathrm{Rc}, \mathrm{Rd}, \mathrm{Re} \text { and } \mathrm{Rg}_{1} \text { ), } \\
\text { polyacetylenes (panaxynol, panaxydol, panaxytriol, } \\
\text { falcarindiol), fatty acids, amino acids, polysaccharides }\end{array}$ \\
\hline & Panax ginseng Korea & $\begin{array}{l}\text { Saponins (ginsenosides } \mathrm{Rb}_{1}, \mathrm{Rb}_{2}, \mathrm{Rc}, \mathrm{Rd}, \mathrm{Re} \text { and } \mathrm{Rg}_{1} \text { ), } \\
\text { polyacetylenes (panaxynol, panaxydol, panaxytriol, } \\
\text { falcarindiol), fatty acids, amino acids, polysaccharides }\end{array}$ \\
\hline & Panax notoginseng & $\begin{array}{l}\text { Saponins (ginsenosides } \mathrm{Rb}_{1}, \mathrm{Rb}_{2}, \mathrm{Rc}, \mathrm{Rd}, \mathrm{Re} \text { and } \mathrm{Rg}_{1} \text { ), } \\
\text { polyacetylenes (panaxynol, panaxydol, panaxytriol, } \\
\text { falcarindiol), fatty acids, amino acids, polysaccharides }\end{array}$ \\
\hline Arecaceae & Areca catechu & $\begin{array}{l}\text { Alkaloids (arecoline, arecaidin, arecolidin, } \\
\text { guvacolin, guvacin) }\end{array}$ \\
\hline Asclepiadaceae & Cynanchum paniculatum & Glucosides (cynanchocerin, cynanchin) \\
\hline
\end{tabular}


Table 2. Cont.

\begin{tabular}{|c|c|c|}
\hline Family & Species & Main Compounds \\
\hline \multirow[t]{10}{*}{ Asteraceae } & Artemisia апnиа & $\begin{array}{l}\text { Sesquiterpene lactones (artemisinin, arteannuin, } \\
\text { artemisitene), monoterpenes ( } 1,8 \text { cineol, borneol, } \\
\text { camphor, menthol), coumarins (coumarin, scopoletin) }\end{array}$ \\
\hline & Artemisia capillaris & $\begin{array}{l}\text { Sesquiterpene lactones, monoterpenes (1,8 cineol, } \\
\text { borneol, camphor, menthol), coumarins } \\
\text { (coumarin, scopoletin) }\end{array}$ \\
\hline & Arctium lappa & $\begin{array}{l}\text { Monoterpenes, polyacetylenes (falcarinol), fatty } \\
\text { acids, sterols }\end{array}$ \\
\hline & Centipeda minima & $\begin{array}{l}\text { Monoterpenes (thymol), terpene glycosids, } \\
\text { sesquiterpene lactones }\end{array}$ \\
\hline & Chrysanthemum indicum & $\begin{array}{l}\text { Monoterpenes (1,8-cineole, pinene, borneol, } \\
\text { camphor), tannins }\end{array}$ \\
\hline & Chrysanthemum morifolium & $\begin{array}{l}\text { Monoterpenes (1,8-cineole, pinene, borneol, } \\
\text { camphor), tannins }\end{array}$ \\
\hline & Eclipta prostrata & $\begin{array}{l}\text { Monoterpenes, volatile compounds (Heptadecane, } \\
\text { 6,10,14-trimethyl-2-pentadecanone, n-hexadecanoic } \\
\text { acid, pentadecane, eudesma-4(14),11-diene, phytol, } \\
\text { octadec-9-enoic acid, 1,2-benzenedicarboxylic acid } \\
\text { diisooctyl ester, (Z,Z)-9,12-octadecadienoic acid) }\end{array}$ \\
\hline & Senecio scandens & Pyrrolizidine alkaloids, terpenoids \\
\hline & Siegesbeckia orientalis & Phytosterols ( $\beta$-sitosterol) \\
\hline & Taraxacum officinale & $\begin{array}{l}\text { Sesquiterpene lactones, phenolic acids, triterpene } \\
\text { saponins, inulin, phytosterols ( } \beta \text {-sitosterol) }\end{array}$ \\
\hline \multirow[t]{3}{*}{ Berberidaceae } & Berberis bealei & $\begin{array}{l}\text { Alkaloids (berberine, columbamine, } \\
\text { jatrorrhizine, palmatine) }\end{array}$ \\
\hline & Dysosma versipellis & Flavonoids, podophyllotoxin lignans \\
\hline & Epimedium koreanum & $\begin{array}{l}\text { Flavonoids (quercetin, maohuoside B, epimedin A, } \\
\text { epimedin B, icariin, icriside II, icariside I, epimedoside } \\
\text { A, hexandraside E) }\end{array}$ \\
\hline \multirow[t]{3}{*}{ Brassicaceae } & Capsella bursa-pastoris & Flavonoids, terpenes, glucosinolates, saponins, tannins \\
\hline & Isatis indigotica (root) & $\begin{array}{l}\text { Flavonoids, glucosinolates, alkaloids (isatisine A, } \\
\text { indican, isatin, indirubin and indigotin) }\end{array}$ \\
\hline & Isatis indigotica (leaf) & $\begin{array}{l}\text { Flavonoids, glucosinolates, alkaloids (isatisine A, } \\
\text { indican, isatin, indirubin, indigotin) }\end{array}$ \\
\hline Caprifoliaceae & Lonicera confusa & $\begin{array}{l}\text { Flavonoids (rutin, quercetin, } \\
\text { luteilin-7-O-beta-D-galactoside, lonicerin), chlorogenic } \\
\text { acid, beta-sitosterol, tetratriacontane) }\end{array}$ \\
\hline Convallariaceae & Polygonatum kingianum & Flavonoids, steroidal saponins \\
\hline Crassulaceae & Rhodiola rosea & Glucosides (salidroside, tyrosol) \\
\hline Cupressaceae & Platycladus orientalis & Monoterpenes \\
\hline Dryopteridaceae & Cyrtomium fortunei & Flavonoids \\
\hline Ephedraceae & Ephedra sinica & Phenylethylamine alkaloids (ephedrine) \\
\hline Equisetaceae & Equisetum hiemale & Flavonoids, silicic acids \\
\hline
\end{tabular}


Table 2. Cont.

\begin{tabular}{|c|c|c|}
\hline Family & Species & Main Compounds \\
\hline Euphorbiaceae & Croton tiglium & $\begin{array}{l}\text { Glyceryl crotonate, crotonic acid, crotonic resin, } \\
\text { phorbol esters (phorbol formate, phorbol butyrate, } \\
\text { phorbol crotonate) }\end{array}$ \\
\hline \multirow[t]{7}{*}{ Fabaceae } & Abrus cantoniensis & Lectins, indolalkaloids \\
\hline & Acacia catechu & Flavonoids (quercetin, rutin), catechin, epicatechin \\
\hline & Cassia tora & $\begin{array}{l}\text { Flavonoids, dianthrone glycosides (sennoside A, B), } \\
\text { anthraquinones (anthrones, emodin, rhein) }\end{array}$ \\
\hline & Desmodium styracifolium & Monoterpenes, alkaloids \\
\hline & Glycyrrhiza inflata & $\begin{array}{l}\text { Flavonoids, isoflavonoids, chalcone (liquiritin, } \\
\text { isoliquiritin), saponins (glycyrrhizic acid, } \\
\text { 4-hydroxy-glycyrrhtinic acid), monoterpenes } \\
\text { (1-(2-Furyl)propan-2-one), pyrazine } \\
\text { (2-acetyl-1-furfuryl pyrrole), benzene } \\
\text { (1-methoxy-4-isopropylbenzene) }\end{array}$ \\
\hline & Spatholobus suberectus & Flavonoids, catechin, pyranoside \\
\hline & Sutherlandia frutescens & Flavonoids, triterpene saponins, L-canavanin, pinitol \\
\hline \multirow[t]{2}{*}{ Geraniaceae } & Geranium wilfordii & Flavonoids, tannins, monoterpenes \\
\hline & Pelargonium sidoides & Flavonoids, tannins, coumarines, monoterpenes \\
\hline Ginkgoaceae & Ginkgo biloba & $\begin{array}{l}\text { Flavonoids (glycosides of kaempferol, quercetin, } \\
\text { isorhamnetin), bisflavonoids, proanthocyanidins, } \\
\text { ginkgolic acid, the sesqiterpene alcohol bilobalide, } \\
\text { terpene lactones, diterpene lactones (ginkgolides) }\end{array}$ \\
\hline Hypericaceae & Hypericum japonicum & $\begin{array}{l}\text { Hypericin, hyperforin, monoterpenes, flavonoids, } \\
\text { tannins, saponins }\end{array}$ \\
\hline Iridaceae & Belamcanda chinensis & Flavonoids (belamcandin, iridin) \\
\hline \multirow[t]{3}{*}{ Lamiaceae } & Mentha haplocalyx & Monoterpenes (menthol) \\
\hline & Prunella vulgaris & $\begin{array}{l}\text { Triterpene saponins, flavonoids (rutin) tannins, } \\
\text { rosmarinic acid, monoterpenes (camphor) }\end{array}$ \\
\hline & Scutellaria baicalensis & Flavonoids, iridoid glycosides \\
\hline Lauraceae & Cinnamomum cassia & $\begin{array}{l}\text { Monoterpenes (1,8-cineol, pinene, cinnamaldehyde), } \\
\text { coumarins, tannins }\end{array}$ \\
\hline Loranthaceae & Taxillus chinensis & Flavonoids (avicularin, quercetin) \\
\hline Lythraceae & Punica granatum & Tannins (punicalin, punicalagin), piperidine alkaloids \\
\hline Magnoliaceae & Magnolia officinalis & $\begin{array}{l}\text { Tannins, flavonoids (rutin), sesquiterpenes, } \\
\text { monoterpenes (1,8-cineol) }\end{array}$ \\
\hline Melanthiaceae & Paris polyphylla & Steroidal saponins (dioscin, polyphyllin D) \\
\hline Myrsinaceae & Lysimachia christinae & Flavonoids, tannins, triterpene saponins \\
\hline Myrtaceae & Eucalyptus robusta & Monoterpenes (1,8-cineol) sesquiterpenes \\
\hline Ophioglossaceae & Ophioglossum vulgatum & Quercetin 3-O-methyl ether, ophioglonin \\
\hline Orchidaceae & Dendrobium loddigesii & Alkaloids (dendrobine, nobiline) \\
\hline Paeoniaceae & Paeonia lactiflora & $\begin{array}{l}\text { Flavonoids, (kaempferol), } \beta \text {-sitosterol, resveratrol } \\
\text { derivatives, phytoestrogens, monoterpene glycosid } \\
\text { (paeoniflorin) }\end{array}$ \\
\hline Pedaliaceae & Harpagophytum procumbens & Iridoid glycosides (harpagide, harpagoside) \\
\hline
\end{tabular}


Table 2. Cont.

\begin{tabular}{|c|c|c|}
\hline Family & Species & Main Compounds \\
\hline Poaceae & Cymbopogon distans & $\begin{array}{l}\text { Monoterpenes (1,8-cineol, pinene, cymbopogone, } \\
\text { cymbopogonol) }\end{array}$ \\
\hline \multirow[t]{4}{*}{ Polygonaceae } & $\begin{array}{l}\text { Fallopia japonica (syn. } \\
\text { Polygonum cuspidatum) }\end{array}$ & $\begin{array}{l}\text { Anthraquinones (emodin, rhein, chrysophanol), } \\
\text { tetrahydroxystilbene glucosides, steroidal } \\
\text { saponins, tannins }\end{array}$ \\
\hline & $\begin{array}{l}\text { Fallopia multiflora (syn. } \\
\text { Polygonum multiflorum) }\end{array}$ & Flavonoids, tannins \\
\hline & Polygonum aviculare & Flavonoids, tannins \\
\hline & Rheum officinale & $\begin{array}{l}\text { Flavonoids, tannins, anthraquinone glycosides } \\
\text { (emodin, rhein) }\end{array}$ \\
\hline Ranunculaceae & Coptis chinensis & $\begin{array}{l}\text { Alkaloids (berberine, palmatine, coptisine, columbamine, } \\
\text { epiberberine) }\end{array}$ \\
\hline \multirow[t]{3}{*}{ Rosaceae } & Rosa chinensis & Flavonoids, tannins, carotinoids, vitamin C \\
\hline & Rosa laevigata & Flavonoids, tannins, carotinoids, vitamin $\mathrm{C}$ \\
\hline & Sanguisorba officinalis & Tannins, flavonoids, saponins, proanthocyanidins \\
\hline Rubiaceae & Hedyotis diffusa & Iridoid glycosides \\
\hline \multirow[t]{3}{*}{ Rutaceae } & Evodia lepta & Indole alkaloids, (evodiamin, rutecarpin), chromenes \\
\hline & Evodia rutaecarpa & Indole alkaloids, (evodiamin, rutecarpin) \\
\hline & Phellodendron chinense & $\begin{array}{l}\text { Isoquinoline alkaloids (berberine, palmatine, } \\
\text { jatrorrhizine), sesquiterpene lactones }\end{array}$ \\
\hline Saururaceae & Houttuynia cordata & $\begin{array}{l}\text { Flavonoids (quercetin, quercetin 3-rhamnoside), } \\
\text { norcepharadione B }\end{array}$ \\
\hline Schisandraceae & Kadsura longipedunculata & $\begin{array}{l}\text { Lignans (kadsurilignans), triterpenoid acids, triterpene } \\
\text { dilactones, camphene, borneol }\end{array}$ \\
\hline Selaginellaceae & Selaginella tamariscina & $\begin{array}{l}\text { Flavonoids (amentoflavone, isocryptomerin, } \\
\text { biflavonoids), sterols }\end{array}$ \\
\hline Valerianaceae & Patrinia scabiosaefolia & Triterpene saponins, iridoid glycosides (patrinoside) \\
\hline Verbenaceae & Verbena officinalis & Iridoid glycosides, flavonoids \\
\hline Violaceae & Viola yezoensis & Flavonoids, saponins \\
\hline \multirow[t]{2}{*}{ Zingiberaceae } & Alpinia galanga & $\begin{array}{l}\text { Monoterpenes (camphor, cineole, d-pinene, eugenol, } \\
\text { cadinene), flavonoids (galangin, riboflavin), niacin, } \\
\text { 1'-acetoxychavicol acetate, ascorbic acid }\end{array}$ \\
\hline & Alpinia oxyphylla & $\begin{array}{l}\text { Monoterpenes (camphor, cineole, d-pinene, eugenol, } \\
\text { cadinene), flavonoids (galangin, riboflavin), niacin, } \\
\text { 1'-acetoxychavicol acetate, ascorbic acid }\end{array}$ \\
\hline
\end{tabular}

Hepatitis B and hepatitis C are responsible for $75 \%$ of all cases of liver diseases worldwide, often causing cirrhosis and hepatocellular carcinoma [14,15]. Hepatitis B and hepatitis C account for the most problematic viral infections, since the standard treatment with pegylated IFN- $\gamma$ and the purine nucleoside analogues lamivudine and ribavirin have severe side effects while being at the same time ineffective for $50 \%$ of the patients [14,16]. Thus, new drugs are urgently needed [17]. Together with the bovine viral diarrhoea virus (BVDV), and the Japanese Encephalitis virus, hepatitis C virus (HCV) belongs to the Flaviviridae family. As BVDV, whose cytopathic strains induce a lytic infection in 
some cell lines, such as embryonic bovine trachea (EBTr) cells, is easier to manipulate and lacks human infectivity, this is commonly used as in vitro model for infections of this viral family [18].

Our knowledge of the natural products of many plants used in European and Chinese phytomedicine is broad (Table 2), however, many new discoveries are still possible. Previously, several studies demonstrated the promising potential of traditional phytomedicine for the discovery of new antiviral drugs. Artemisinin and related compounds proved effective in screening assays against viral hepatitis [6,7,19]. In water extracts of Terminalia chebula, Sanguisorba officinalis, Rubus coreanus and Rheum palmatum, Kim et al. [20] discovered prominent anti-hepatitis B virus (HBV) activities. The ethanolic extract of Hypericum perforatum, a well-established drug for treatment of depression [9] was also shown to be active against the HBV [21]. Laxative anthraquinones isolated from Rheum palmatum demonstrated significant effects against HBV [22] and saikosaponins from Bupleurum species were previously shown to lower significantly the HBV level in the HepG2 2.2.15 assay [23]. HepG2 2.2.15 is a stable cell line infected with the HBV. The assay measures the production of secreted HBV from the cell by using real time quantitative PCR.

Parasites such as protozoa and helminths cause a major health threat in many tropical countries [24], while suitable drugs are still rare [25]. Blood parasites of the genus Trypanosoma (Trypanosoma brucei rhodesiense and T. b. gambiense) are responsible for African trypanosomiasis (sleeping sickness) with serious consequences for human health and economy. Due to the high infectivity of African human trypanosomes, $T$. $b$. brucei is commonly used as model organism with similar morphology and biochemical processes, while being only infective for cattle [24,26,27]. This subspecies causes the cattle epidemic nagana, it is responsible for severe financial loss of 1340 billion USD per year [28].

Currently, only four drugs are approved internationally for the treatment of humans against sleeping sickness: suramin, pentamidine, melarsoprol and eflornithine. Diminazene, another effective antitrypanosomal drug, is only approved for the use on animals because of severe side effects [24]. Even the drugs approved for human use are responsible for serious side effects, and furthermore, the parasites develop increasing resistance to them [29-32]. This situation makes the discovery of new, effective drugs an urgent task of the 21st century [33-35].

When considered together, enterohepatic tumors, i.e., those affecting the liver, the biliary duct, gallbladder and the intestine, constitute the first cause of death due to cancer. Although in many cases surgery and radiotherapy are efficacious, these therapeutic strategies cannot always be applied. Moreover, even when the removal of tumors is possible, pre- and post-operative pharmacological adjuvant regimens are often needed. However, one important limitation to the use of cytostatic drugs to treat enterohepatic tumors is that they generally exhibit marked resistance to currently available pharmacological approaches and the development of resistance during treatment [36].

Many natural products and derivatives thereof belong to the standard repertoire of cancer chemotherapy. Examples are Vinca alkaloids, such as vincristine, vinblastine and vinorelbine, obtained from Madagascar periwinkle (Catharanthus rosea). Also taxanes such as paclitaxel and docetaxel, which are produced from the bark of Pacific yew (Taxus), podophyllotoxins, such as etoposide and teniposide, derivatives of the genus Podophyllum, and camptothecin, derived from the Asian "Tree of Happiness" (Camptotheca acuminata) and its derivatives, irinotecan and topotecan, are natural products from TCM plants [4]. 
In this study, extracts from 82 traditional medicinal plants were screened against $\mathrm{HBV}$ and flaviviruses, T. b. brucei and several cancer cell lines. Our aim was to detect new sources of active compounds for the possible treatment of these important causes of diseases.

\section{Experimental Section}

\subsection{Chemicals}

Dimethylsulfoxide (DMSO), trypsin-EDTA, DMEM and MEM with GLUTAMAX media, fetal bovine serum (FBS) and supplementary chemicals were bought from Gibco ${ }^{\circledR}$ Invitrogen; Germany. Antibiotic/antimycotic solution, gentamicin, Neutral Red (NR, 3-amino-7-dimethylamino-2-methylfenazine), $\mathrm{NaHCO}_{3}$, L-glutamine and MEM media were purchased from Sigma-Aldrich (Madrid, Spain). Geneticin ${ }^{\circledR}$ (G418) was from Roche (Barcelona, Spain). Dried TCM plants were obtained in Shanghai; South African plants were provided by Prof. van Wyk, University of Johannesburg, South Africa.

\subsection{Authentication of Plant Material}

The TCM plants were genetically identified by DNA barcoding to confirm the identity and to exclude adulterations. DNA was isolated from plant drugs; their chloroplast $r b c \mathrm{~L}$ gene was amplified and sequenced. The obtained sequences were authenticated with sequences obtained from sample species of the Botanical Garden of Heidelberg and databases. Voucher specimens of the plant material were deposited at the Department of Biology, Institute of Pharmacy and Molecular Biotechnology, Heidelberg University, Germany. Additionally, the plants were authenticated by visual and microscopic techniques.

\subsection{Extract Preparation}

Five hundred grams of dry plant material was powdered and extracted with dichloromethane, methanol and water under moderate heat using a reflux condenser for 4 hours. The extracts obtained were concentrated using the rotation evaporator, stored at $-40{ }^{\circ} \mathrm{C}$ under exclusion of light and dried under vacuum prior to the experiments. Dried extracts were dissolved in DMSO for the experiments.

\subsection{Test Organisms}

T. b. brucei TC 221 were originally obtained from Prof. Peter Overath (Max-Plank Institut für Biologie, Tübingen) by Dr. D. Steverding before being cultured at the IPMB, Heidelberg since 1999. HeLa cancer cells and Cos7 fibroblast cells (African green monkey kidney cells immortalized with the monkey virus SV40) were cultured at the IPMB, Heidelberg for several years; Hep G2, SK-Hep1 and LS 174T, HepG2 2.2.15 and EBTr cells were cultured at the Laboratory of Experimental Hepatology and Drug Targeting (HEVEFARM), University of Salamanca, CIBERehd, Spain. 


\subsection{Methods}

Cancer Cells (HeLa, Hep G2, SK-Hep1 and LS $174 \mathrm{~T}$ ) were basically grown as previously described [37], HeLa and Cos 7 cells were grown at $37{ }^{\circ} \mathrm{C}$ with $5 \% \mathrm{CO}_{2}$ in DMEM complete media (10\% heat-inactivated FBS; 5\% penicillin/streptomycin; 5\% non-essential amino acids). Hep G2, SK-Hep1, and LS $174 \mathrm{~T}$ cells were grown at $37{ }^{\circ} \mathrm{C}$ with $5 \% \mathrm{CO}_{2}$ in MEM complete media (10\% heat-inactivated FBS; $1 \%$ antibiotic-antimycotic solution).

HepG 2.2.15 cells were cultured as previously described [7] in DMEM complete medium with 10\% FBS, geneticin and gentamicin. EBTr cells were cultured as described elsewhere [6], they were maintained in MEM-GLUTAMAX medium with $10 \%$ heat-inactivated FBS; $1 \%$ penicillin/streptomycin, and $0.1 \%$ gentamicin.

T. b. brucei TC221 cells were cultured in BALTZ medium [38] supplemented with $20 \%$ inactivated FBS and $0.001 \% \beta$-mercaptoethanol.

The MTT cell viability assay was used to determine cytotoxicity in Cos7 and HeLa cells [39,40]. Cells during the logarithmic growth period were seeded in 96 well plates (Greiner Labortechnik) at concentrations of $2 \times 10^{4}$ cells/well and grown for $24 \mathrm{~h}$. Dried and powdered extracts were dissolved in DMSO before being serially diluted to 10 concentrations in 96 well plates. Cells were incubated with the extract for $24 \mathrm{~h}$ before the medium was removed and replaces with fresh medium containing $0.5 \mathrm{mg} / \mathrm{mL}$ 3-(4,5-dimethylthiazol-2-yl)-2,5-diphenyltetrazolium bromide (MTT). The formazan crystals were dissolved in DMSO $4 \mathrm{~h}$ later; the absorbance was measured at $570 \mathrm{~nm}$ with a Tecan Safire II Reader.

T. b. brucei TC221 cell viability was additionally to the MTT assay confirmed and evaluated using microscopic techniques.

Toxicity of the extracts for T. b. brucei was compared to HeLa and Cos7 cells and the Selectivity index (SI) was calculated. SI: ratio of the $\mathrm{IC}_{50}$ value of mammalian cells divided by the $\mathrm{IC}_{50}$ value of trypanosomes.

To test the antiproliferative effect, $5 \times 10^{3}$ or $15 \times 10^{3}$ cells per well (depending on the cell line) were seeded in 96 well plates and incubated with 5,10, 25, 50, 100, and $200 \mu \mathrm{g} / \mathrm{mL}$ water extract for $72 \mathrm{~h}$. The cell viability was also determined using the MTT assay with minor modifications. Acute toxicity was similarly measured using MTT assay but after short-term $(6 \mathrm{~h})$ incubation with the extracts at the concentrations of $\mathrm{IC}_{50}$ calculated for each cell line.

To determine the antiviral effect of the extracts, BVDV was used here as a substitute in vitro model for HCV infection. Bovine epithelial cells obtained from embryonic trachea (EBTr) were cultured in MEM with GLUTAMAX medium as described previously [6]. They were seeded in 96 well plates $\left(15 \times 10^{3}\right.$ cells/well; $50 \mu \mathrm{L} /$ well $)$ and left to attach for $2 \mathrm{~h}$. Afterwards, the cells were infected with $50 \mu \mathrm{L} /$ well of the desired dilution in culture medium of an initial suspension of BVDV (cytopathic strain Oregon C24V, genotype I, subgenotype b) to reach $40 \%$ cytopathic effect. After 48 $\mathrm{h}$ of incubation the medium was replaced with dilutions in culture medium of the extracts $(1,5,10,50$, $100 \mu \mathrm{g} / \mathrm{mL}$ ). The viability of the EBTr cells was measured using the MTT assay after $72 \mathrm{~h}$ incubation.

An HBV antiviral assay based on the HepG2 2.2.15 model was used to determine the antiviral activity of the extracts [41]. HepG2 2.2 .15 cells were seeded in six-wells plates $\left(35 \times 10^{4}\right.$ per well) before being incubated for 21 days with $50 \mu \mathrm{g} / \mathrm{mL}, 25 \mu \mathrm{g} / \mathrm{mL}$ and $12.5 \mu \mathrm{g} / \mathrm{mL}$ extract. The culture 
medium was replaced every 3 days with fresh medium, containing the extract dilutions. Quantitative real-time PCR (QPCR) was used to measure the HBV-DNA levels in the culture medium (representing HBV virion production) as described previously [7]. Cytotoxicity was determined using the uptake of NR dye at the end of treatment [42].

At least three cultures for each experimental condition were carried out. Data points were obtained in triplicate form (T. b. brucei, cancer cell lines, Cos7, HepG2 2.2 .15 cells) and in 8 different wells (EBTr). The $\mathrm{IC}_{50}$ value was calculated using SigmaPlot ${ }^{\circledR} 11.0$ (4 parameter logistic curve). Statistical significance determined via paired t-test or the Bonferroni method of multiple-range testing.

\section{Results and Discussion}

The great diversity of natural products occurring plants is of the utmost importance for the discovery of new pharmaceutical lead compounds. Through millions of years of evolution the defence mechanisms of plants were perfected. The great variety of natural products clearly demonstrates the efficacy of this defence strategy against herbivores, but also fungi, bacteria and viruses (Table 2). In many cases the plants do not rely on specific interactions but also rely on unspecific molecules that interact with a great number of targets (Table 1). Of highest importance are the interactions with free amino and free SH groups. While aldehydes, isothiocyanates and epoxids are able to form covalent bonds with free amino groups, sesquiterpene lactones, disulfides, polyacetylenes and epoxides interact with free SH groups. Phenolic OH-groups interact on a non-covalent basis with free amino groups by forming strong hydrogen and ionic bonds.

The cytotoxicity of water and organic solvent extracts from 82 medicinal plants was determined in the fibroblast cells Cos7 and in four cancer cell lines: HeLa, HepG2, SK-Hep1 and LS 174T (Tables 3 and 4). The aqueous extracts were also screened against BVDV and HBV (Table 3), whereas organic solvent extracts were assayed on T. b. brucei (Table 4). Our results revealed promising results in order to use several of these plants as sources for therapeutic agents.

The viral particles offer three main targets to the natural products (Table 1). They can interact with the surface proteins, the biomembrane and the DNA or RNA. While most plants interact unselectively with the virus, selective interactions do also occur.

10 plants demonstrated antiviral protection against BVDV in combination with low cytotoxicity. Four plants (Panax ginseng, Cassia tora, Ginkgo biloba and Viola yezoensis) exerted protective antiviral effect only at high doses, whereas other six plant extracts (Celosia cristata, Ophioglossum vulgatum, Houttuynia cordata, Selaginella tamariscina, Alpinia galanga and Alpinia oxyphylla) were effective at lower concentrations (Table 3).

Regarding the six plants with higher potential interest as a source of anti-HCV drugs, antiviral glycoproteins, CCP-25 and CCP-27, purified from the leaves of Celosia cristata [43] have been previously studied [44-48]. Their ability to inhibit viral RNA translation activities against several plant viruses have been described [49]. 
Table 3. Cytotoxicity against cancer cells, Cos7 fibroblasts, and antiviral activity against HBV and flaviviruses of water extracts obtained from 82 medicinal plants.

\begin{tabular}{|c|c|c|c|c|c|c|c|c|c|c|c|c|}
\hline \multirow[b]{2}{*}{ Family } & \multirow[b]{2}{*}{ Species } & \multirow[b]{2}{*}{ IPMB/No. } & \multirow[b]{2}{*}{ GenBank } & \multicolumn{5}{|c|}{ Antiumor Effect } & \multicolumn{4}{|c|}{ Antiviral Effect } \\
\hline & & & & $\begin{array}{c}\text { Cos } 7 \\
\mathrm{IC}_{50} \\
(\mu \mathrm{g} / \mathrm{mL})\end{array}$ & $\begin{array}{c}\text { HeLa } \\
\mathrm{IC}_{50} \\
(\mu \mathrm{g} / \mathrm{mL})\end{array}$ & $\begin{array}{c}\text { HepG2 } \\
\text { IC }_{50} \\
(\mu \mathrm{g} / \mathrm{mL})\end{array}$ & $\begin{array}{c}\text { SK-Hep1 } \\
\text { IC }_{50} \\
(\mu \mathrm{g} / \mathrm{mL})\end{array}$ & $\begin{array}{c}\text { LS 174T } \\
\text { IC }_{50} \\
(\mu \mathrm{g} / \mathrm{mL})\end{array}$ & $\begin{array}{c}{ }^{a} \text { anti-BVDV } \\
\text { Toxicity } \\
\text { on EBTr } \\
\text { cells }\end{array}$ & $\begin{array}{c}{ }^{b} \text { anti-BVDV } \\
\text { protection } \\
\text { in EBTr } \\
\text { cells }\end{array}$ & $\begin{array}{c}{ }^{c} \text { anti-HBV } \\
\text { effect in } \\
\text { Hep G2 } \\
2.2 .15\end{array}$ & $\begin{array}{c}{ }^{d} \text { Toxicity } \\
\text { at effective } \\
\text { doses }\end{array}$ \\
\hline Acanthaceae & $\begin{array}{l}\text { Andrographis } \\
\text { paniculata }\end{array}$ & P6838/04 & JF949965 & 255.6 & 576.0 & 170 & 80 & $>200$ & 0 & 0 & ++ & ++ \\
\hline Amaranthaceae & Celosia cristata & P6848/14 & JF949970 & 263.9 & 2773.5 & 200 & 180 & $>200$ & 0 & ++ & 0 & ND \\
\hline \multirow[t]{5}{*}{ Apiaceae } & Bupleurum chinense & P6844/10 & JF950021 & 15.6 & 339.3 & 120 & 100 & 100 & ++ & 0 & ND & ND \\
\hline & $\begin{array}{l}\text { Bupleurum } \\
\text { marginatum }\end{array}$ & P6845/11 & JF949968 & 350.6 & 838.1 & ND & ND & ND & ND & ND & ND & ND \\
\hline & Centella asiatica & P6849/15 & JF950022 & 325.8 & 1436.8 & $>200$ & 40 & 70 & ++++ & 0 & 0 & ND \\
\hline & Cnidium monnieri & P6854/20 & JF949973 & 339.7 & 775.5 & $>200$ & $>200$ & $>200$ & ++++ & 0 & 0 & ND \\
\hline & $\begin{array}{l}\text { Saposhnikovia } \\
\text { divaricata }\end{array}$ & P6902/68 & JF949988 & 153.0 & 1024.7 & $>200$ & 200 & 155 & ++ & 0 & ++ & ++ \\
\hline \multirow[t]{3}{*}{ Araliaceae } & $\begin{array}{l}\text { Eleutherococcus } \\
\text { senticosus }\end{array}$ & P6919/79 & - & 130.5 & 430.0 & $>200$ & 125 & 160 & ++ & ++ & 0 & ND \\
\hline & Panax ginseng & P8088/81 & JF950028 & 151.7 & 2594.6 & $>200$ & 140 & $>200$ & 0 & + & 0 & 0 \\
\hline & Panax notoginseng & $\mathrm{P} 6887 / 53$ & JF950030 & 182.3 & 1574.9 & $>200$ & $>200$ & 200 & 0 & 0 & ND & ND \\
\hline Arecaceae & Areca catechu & P6840/06 & - & 16.6 & 378.1 & 40 & 21 & 90 & ++++ & 0 & ND & ND \\
\hline Asclepiadaceae & $\begin{array}{l}\text { Cynanchum } \\
\text { paniculatum }\end{array}$ & P6858/24 & JF949975 & 220.7 & 693.9 & $>200$ & 130 & $>200$ & ++ & ++ & 0 & ND \\
\hline
\end{tabular}


Table 3. Cont.

\begin{tabular}{|c|c|c|c|c|c|c|c|c|c|c|c|c|}
\hline \multirow[b]{2}{*}{ Family } & \multirow[b]{2}{*}{ Species } & \multirow[b]{2}{*}{ IPMB/No. } & \multirow[b]{2}{*}{ GenBank } & \multicolumn{5}{|c|}{ Antiumor Effect } & \multicolumn{4}{|c|}{ Antiviral Effect } \\
\hline & & & & $\begin{array}{c}\text { Cos } 7 \\
\text { IC }_{50} \\
(\mu \mathrm{g} / \mathrm{mL})\end{array}$ & $\begin{array}{c}\text { HeLa } \\
\text { IC }_{50} \\
(\mu \mathrm{g} / \mathrm{mL})\end{array}$ & $\begin{array}{c}\text { HepG2 } \\
\text { IC }_{50} \\
(\mu \mathrm{g} / \mathrm{mL})\end{array}$ & $\begin{array}{c}\text { SK-Hep1 } \\
\text { IC }_{50} \\
(\mu \mathrm{g} / \mathrm{mL})\end{array}$ & $\begin{array}{c}\text { LS 174T } \\
\text { IC }_{50} \\
(\mu \mathrm{g} / \mathrm{mL})\end{array}$ & $\begin{array}{c}a_{\text {anti-BVDV }} \\
\text { Toxicity } \\
\text { on EBTr } \\
\text { cells }\end{array}$ & $\begin{array}{c}{ }^{b} \text { anti-BVDV } \\
\text { protection } \\
\text { in EBTr } \\
\text { cells } \\
\end{array}$ & $\begin{array}{c}{ }^{c} \text { anti-HBV } \\
\text { effect in } \\
\text { Hep G2 } \\
2.2 .15 \\
\end{array}$ & $\begin{array}{c}{ }^{d} \text { Toxicity } \\
\text { at effective } \\
\text { doses }\end{array}$ \\
\hline \multirow[t]{10}{*}{ Asteraceae } & Artemisia annua & P6841/07 & JF949966 & 288.6 & 775.5 & 177 & 50 & $>200$ & ++++ & 0 & ++ & ++ \\
\hline & Artemisia capillaris & P6842/08 & JF949967 & 201.9 & 561.7 & 142 & 30 & $>200$ & ++ & 0 & ++ & ++ \\
\hline & Arctium lappa & P6839/05 & JF949994 & 355.5 & 516.3 & 200 & 5 & $>200$ & ++ & 0 & 0 & ND \\
\hline & Centipeda minima & $\mathrm{P} 6850 / 16$ & - & 55.6 & 207.2 & 72 & 0,5 & 130 & ++ & ++ & ND & ND \\
\hline & $\begin{array}{l}\text { Chrysanthemum } \\
\text { indicum }\end{array}$ & P6851/17 & JF949971 & 320.9 & 583.4 & 130 & 8 & 200 & ++++ & 0 & 0 & ND \\
\hline & $\begin{array}{l}\text { Chrysanthemum } \\
\text { morifolium }\end{array}$ & $\mathrm{P} 6852 / 18$ & JF949972 & 760.4 & 1045.8 & $>200$ & 180 & $>200$ & ++ & 0 & 0 & ND \\
\hline & Eclipta prostata & P6863/29 & JF950000 & 291.7 & 667.0 & $>200$ & 30 & 120 & ++ & ++ & 0 & ND \\
\hline & Senecio scandens & P6905/71 & JF949989 & 114.2 & 607.9 & 3.5 & 50 & 25 & ++++ & ++ & ND & ND \\
\hline & $\begin{array}{l}\text { Siegesbeckia } \\
\text { orientalis }\end{array}$ & P6906/72 & JF949990 & 159.2 & 542.8 & 40 & 100 & 50 & ++ & ++ & ND & ND \\
\hline & Taraxacum officinale & $\mathrm{P} 6908 / 74$ & JF950019 & 156.9 & 708.5 & 130 & 147 & 65 & ++ & ++ & 0 & ND \\
\hline \multirow[t]{3}{*}{ Berberidaceae } & Berberis bealei & P6883/49 & JF949996 & 270.0 & 659.4 & 63 & 60 & 70 & ND & $\mathrm{ND}$ & ND & ND \\
\hline & Dysosma versipellis & $\mathrm{P} 6862 / 28$ & - & 1276.9 & 1274.8 & $>200$ & 3.5 & 3.5 & ++++ & 0 & 0 & ND \\
\hline & Epimedium koreanum & P6865/31 & JF950002 & 140.7 & 280.2 & 5 & 32 & 10 & ++ & 0 & ND & ND \\
\hline \multirow[t]{2}{*}{ Brassicaceae } & Isatis indigotica (root) & P6877/43 & JF949981 & 557.2 & 2427.4 & $>200$ & $>200$ & $>200$ & 0 & 0 & 0 & ND \\
\hline & Isatis indigotica (leaf) & P6878/44 & JF949981 & 93.5 & 1223.5 & 170 & 98 & 80 & ++ & ++ & 0 & ND \\
\hline Caprifoliaceae & Lonicera confusa & $\mathrm{P} 6880 / 46$ & JF949982 & 446.8 & 812.2 & $>200$ & $>200$ & $>200$ & ++ & 0 & 0 & ND \\
\hline Convallariaceae & $\begin{array}{l}\text { Polygonatum } \\
\text { kingianum }\end{array}$ & P6892/58 & JF950027 & 298.4 & 2321.7 & $>200$ & 130 & 42 & ++ & 0 & 0 & ND \\
\hline Crassulaceae & Rhodiola rosea & $\mathrm{P} 6920 / 84$ & - & 61.9 & 144.4 & 160 & 110 & 40 & ++ & ++ & 0 & ND \\
\hline Cupressaceae & Platycladus orientalis & $\mathrm{P} 6891 / 57$ & JF950011 & 97.7 & 428.2 & $>200$ & 155 & 10 & ++ & 0 & 0 & ND \\
\hline
\end{tabular}


Table 3. Cont.

\begin{tabular}{|c|c|c|c|c|c|c|c|c|c|c|c|c|}
\hline \multirow[b]{2}{*}{ Family } & \multirow[b]{2}{*}{ Species } & \multirow[b]{2}{*}{ IPMB/No. } & \multirow[b]{2}{*}{ GenBank } & \multicolumn{5}{|c|}{ Antiumor Effect } & \multicolumn{4}{|c|}{ Antiviral Effect } \\
\hline & & & & $\begin{array}{c}\operatorname{Cos} 7 \\
\mathrm{IC}_{50} \\
(\mu \mathrm{g} / \mathrm{mL})\end{array}$ & $\begin{array}{c}\text { HeLa } \\
\text { IC }_{50} \\
(\mu \mathrm{g} / \mathrm{mL})\end{array}$ & $\begin{array}{c}\text { HepG2 } \\
\text { IC }_{50} \\
(\mu \mathrm{g} / \mathrm{mL})\end{array}$ & $\begin{array}{c}\text { SK-Hep1 } \\
\text { IC }_{50} \\
(\mu \mathrm{g} / \mathrm{mL})\end{array}$ & $\begin{array}{c}\text { LS 174T } \\
\text { IC }_{50} \\
(\mu \mathrm{g} / \mathrm{mL})\end{array}$ & $\begin{array}{c}{ }^{a} \text { anti-BVDV } \\
\text { Toxicity } \\
\text { on EBTr } \\
\text { cells } \\
\end{array}$ & $\begin{array}{c}{ }^{b} \text { anti-BVDV } \\
\text { protection } \\
\text { in EBTr } \\
\text { cells }\end{array}$ & $\begin{array}{c}{ }^{c} \text { anti-HBV } \\
\text { effect in } \\
\text { Hep G2 } \\
2.2 .15 \\
\end{array}$ & $\begin{array}{c}{ }^{d} \text { Toxicity } \\
\text { at effective } \\
\text { doses }\end{array}$ \\
\hline Dryopteridaceae & Cyrtomium fortunei & $\mathrm{P} 6859 / 25$ & JF949998 & 30.4 & 567.4 & $>200$ & $>200$ & $>200$ & ++ & ++ & 0 & ND \\
\hline Ephedraceae & Ephedra sinica & P6864/30 & JF950001 & 69.1 & 193.1 & 200 & 150 & $>200$ & ++++ & ++ & ND & ND \\
\hline Equisetaceae & Equisetum hiemale & P6866/32 & JF950003 & 265.9 & 1058.2 & 5 & $>200$ & $>200$ & ++ & 0 & $\mathrm{ND}$ & $\mathrm{ND}$ \\
\hline Euphorbiaceae & Croton tiglium & P6856/22 & - & 166.2 & 1052.7 & 140 & 50 & $>200$ & ++++ & 0 & ++ & ++ \\
\hline \multirow[t]{7}{*}{ Fabaceae } & Abrus cantoniensis & $\mathrm{P} 6835 / 01$ & JF949964 & 575.2 & 587.1 & $>200$ & 100 & $>200$ & ++ & ++ & 0 & ND \\
\hline & Acacia catechu & P6836/02 & - & 35.7 & 157.5 & $>200$ & 25 & $>200$ & ++ & ++ & ++ & ++ \\
\hline & Cassia tora & P6847/13 & JF949969 & 481.3 & 1519.3 & $>200$ & 0.5 & $>200$ & 0 & + & ++ & ++ \\
\hline & $\begin{array}{l}\text { Desmodium } \\
\text { styracifolium }\end{array}$ & P6861/27 & JF949976 & 333.5 & 651.4 & $>200$ & $>200$ & 150 & 0 & 0 & 0 & ND \\
\hline & Glycyrrhiza inflata & P6873/39 & JF950025 & 583.9 & 2288.0 & $>200$ & $>200$ & 185 & 0 & 0 & ++++ & 0 \\
\hline & $\begin{array}{l}\text { Spatholobus } \\
\text { suberectus }\end{array}$ & P6907/73 & JF949991 & 16.6 & 174.1 & 100 & 135 & 70 & ++ & 0 & ND & ND \\
\hline & $\begin{array}{l}\text { Sutherlandia } \\
\text { frutescens }\end{array}$ & $\mathrm{tba} / 83$ & - & 857.6 & 1670.7 & $>200$ & 70 & $>200$ & 0 & 0 & 0 & ND \\
\hline \multirow{2}{*}{ Geraniaceae } & Geranium wilfordii & $\mathrm{P} 6867 / 33$ & JF949977 & 225.8 & 62.1 & 80 & 45 & 200 & ++ & ++ & ND & ND \\
\hline & Pelargonium sidoides & $\mathrm{tba} / 82$ & - & 15.2 & 62.2 & 200 & $>200$ & 45 & ++ & 0 & 0 & ND \\
\hline Ginkgoaceae & Ginkgo biloba & $\mathrm{P} 6872 / 38$ & JF950005 & 450.8 & 1717.0 & $>200$ & 9 & $>200$ & 0 & + & 0 & ND \\
\hline Hypericaceae & Hypericum japonicum & $\mathrm{P} 6876 / 42$ & JF949980 & 151.8 & 445.5 & 165 & 80 & 100 & ++ & ++ & 0 & ND \\
\hline Iridaceae & Belamcanda chinensis & P6843/09 & JF949995 & 222.1 & 1378.8 & $>200$ & $>200$ & $>200$ & ++ & 0 & ++ & ++ \\
\hline \multirow[t]{3}{*}{ Lamiaceae } & Mentha haplocalyx & $\mathrm{P} 6884 / 50$ & JF949984 & 285.7 & 519.1 & 70 & 82 & $>200$ & ++++ & 0 & ND & ND \\
\hline & Prunella vulgaris & P6896/62 & JF950013 & 21.5 & 341.3 & 100 & 145 & 80 & ++ & 0 & ND & ND \\
\hline & $\begin{array}{l}\text { Scutellaria } \\
\text { baicalensis }\end{array}$ & P6903/69 & JF950017 & 46.4 & 150.0 & 80 & 50 & 120 & ++ & 0 & ND & ND \\
\hline
\end{tabular}


Table 3. Cont.

\begin{tabular}{|c|c|c|c|c|c|c|c|c|c|c|c|c|}
\hline \multirow[b]{2}{*}{ Family } & \multirow[b]{2}{*}{ Species } & \multirow[b]{2}{*}{ IPMB/No. } & \multirow[b]{2}{*}{ GenBank } & \multicolumn{5}{|c|}{ Antiumor Effect } & \multicolumn{4}{|c|}{ Antiviral Effect } \\
\hline & & & & $\begin{array}{c}\text { Cos } 7 \\
\mathrm{IC}_{50} \\
(\mu \mathrm{g} / \mathrm{mL})\end{array}$ & $\begin{array}{c}\text { HeLa } \\
\mathrm{IC}_{50} \\
(\mu \mathrm{g} / \mathrm{mL})\end{array}$ & $\begin{array}{c}\text { HepG2 } \\
\text { IC }_{50} \\
(\mu \mathrm{g} / \mathrm{mL})\end{array}$ & $\begin{array}{c}\text { SK-Hep1 } \\
\text { IC }_{50} \\
(\mu \mathrm{g} / \mathrm{mL})\end{array}$ & $\begin{array}{c}\text { LS 174T } \\
\text { IC }_{50} \\
(\mu \mathrm{g} / \mathrm{mL})\end{array}$ & $\begin{array}{c}{ }^{a} \text { anti-BVDV } \\
\text { Toxicity } \\
\text { on EBTr } \\
\text { cells }\end{array}$ & $\begin{array}{c}{ }^{b} \text { anti-BVDV } \\
\text { protection } \\
\text { in EBTr } \\
\text { cells }\end{array}$ & $\begin{array}{c}{ }^{c} \text { anti-HBV } \\
\text { effect in } \\
\text { Hep G2 } \\
2.2 .15 \\
\end{array}$ & $\begin{array}{c}{ }^{d} \text { Toxicity } \\
\text { at effective } \\
\text { doses }\end{array}$ \\
\hline Lauraceae & Cinnamomum cassia & P6853/19 & JF950023 & 453.9 & 713.6 & 180 & $>200$ & $>200$ & ++++ & 0 & ++ & ++ \\
\hline Loranthaceae & Taxillus chinensis & P6909/75 & JF949992 & 181.7 & 1023.2 & $>200$ & $>200$ & 155 & 0 & 0 & 0 & ND \\
\hline Lythraceae & Punica granatum & $\mathrm{P} 6897 / 63$ & JF950014 & 8.6 & 152.4 & 100 & 100 & 60 & ++++ & 0 & ND & ND \\
\hline Magnoliaceae & Magnolia officinalis & P6882/48 & JF950008 & 73.0 & 451.5 & ND & ND & ND & ND & ND & ND & ND \\
\hline Melanthiaceae & Paris polyphylla & $\mathrm{P} 6888 / 54$ & JF950010 & 38.4 & 42.6 & 54 & 168 & 8 & ++++ & ++ & ND & ND \\
\hline Myrsinaceae & Lysimachia christinae & $\mathrm{P} 6881 / 47$ & JF949983 & 152.1 & 431.4 & $>200$ & $>200$ & $>200$ & ++ & 0 & 0 & ND \\
\hline Myrtaceae & Eucalyptus robusta & $\mathrm{P} 6868 / 34$ & - & 94.1 & 15.8 & ND & ND & ND & ND & ND & ND & ND \\
\hline Ophioglossaceae & $\begin{array}{l}\text { Ophioglossum } \\
\text { vulgatum }\end{array}$ & P6885/51 & JF950009 & 344.0 & 1780.1 & $>200$ & $>200$ & $>200$ & 0 & ++ & 0 & ND \\
\hline Orchidaceae & $\begin{array}{l}\text { Dendrobium } \\
\text { loddigesii }\end{array}$ & $\mathrm{P} 6860 / 26$ & JF949999 & 104.0 & 294.4 & $>200$ & 70 & 160 & ++ & ++ & 0 & ND \\
\hline Paeoniaceae & Paeonia lactiflora & P6886/52 & JF950026 & 148.2 & 287.3 & $>200$ & $>200$ & 10 & 0 & 0 & ND & ND \\
\hline Pedaliaceae & $\begin{array}{l}\text { Harpagophytum } \\
\text { procumbens }\end{array}$ & $\mathrm{tba} / 80$ & - & 242.9 & 733.4 & 160 & 190 & 100 & ++ & ++ & 0 & ND \\
\hline Poaceae & Cymbopogon distans & $\mathrm{P} 6857 / 23$ & JF949974 & 257.7 & 486.1 & $>200$ & $>200$ & $>200$ & ++++ & 0 & ++ & ++ \\
\hline \multirow[t]{4}{*}{ Polygonaceae } & Fallopia japonica & P6894/60 & JF950004 & 39.8 & 596.4 & $>200$ & $>200$ & 80 & ++++ & ++ & 0 & ND \\
\hline & Polygonum aviculare & P6893/59 & JF950012 & 82.6 & 488.6 & $>200$ & $>200$ & 10 & ++ & 0 & 0 & ND \\
\hline & $\begin{array}{l}\text { Polygonum } \\
\text { multiflorum }\end{array}$ & P6895/61 & JF949987 & 61.3 & 928.0 & ND & ND & ND & ND & ND & ND & ND \\
\hline & Rheum officinale & P6898/64 & JF950015 & 51.5 & 670.9 & 200 & 25 & 200 & ++ & 0 & 0 & ND \\
\hline Ranunculaceae & Coptis chinensis & $\mathrm{P} 6855 / 21$ & JF950024 & 118.3 & 101.0 & 10 & 2 & 18 & ++++ & 0 & ND & ND \\
\hline
\end{tabular}


Table 3. Cont.

\begin{tabular}{|c|c|c|c|c|c|c|c|c|c|c|c|c|}
\hline \multirow[b]{2}{*}{ Family } & \multirow[b]{2}{*}{ Species } & \multirow[b]{2}{*}{ IPMB/No. } & \multirow[b]{2}{*}{ GenBank } & \multicolumn{5}{|c|}{ Antiumor Effect } & \multicolumn{4}{|c|}{ Antiviral Effect } \\
\hline & & & & $\begin{array}{c}\text { Cos } 7 \\
\text { IC }_{50} \\
(\mu g / m L)\end{array}$ & $\begin{array}{c}\text { HeLa } \\
\text { IC }_{50} \\
(\mu \mathrm{g} / \mathrm{mL})\end{array}$ & $\begin{array}{c}\text { HepG2 } \\
\text { IC }_{50} \\
(\mu \mathrm{g} / \mathrm{mL})\end{array}$ & $\begin{array}{c}\text { SK-Hep1 } \\
\text { IC }_{50} \\
(\mu \mathrm{g} / \mathrm{mL})\end{array}$ & $\begin{array}{c}\text { LS 174T } \\
\text { IC }_{50} \\
(\mu \mathrm{g} / \mathrm{mL})\end{array}$ & $\begin{array}{c}{ }^{a} \text { anti-BVDV } \\
\text { Toxicity } \\
\text { on EBTr } \\
\text { cells } \\
\end{array}$ & $\begin{array}{c}{ }^{b} \text { anti-BVDV } \\
\text { protection } \\
\text { in EBTr } \\
\text { cells } \\
\end{array}$ & 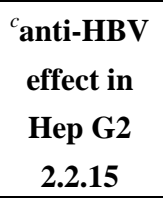 & $\begin{array}{c}{ }^{d} \text { Toxicity } \\
\text { at effective } \\
\text { doses }\end{array}$ \\
\hline \multirow[t]{3}{*}{ Rosaceae } & Rosa chinensis & P6899/65 & - & 24.3 & 135.8 & ND & ND & ND & ND & ND & ND & ND \\
\hline & Rosa laevigata & P6900/66 & - & 93.6 & 781.7 & 190 & 135 & 60 & ++ & ++ & 0 & ND \\
\hline & $\begin{array}{l}\text { Sanguisorba } \\
\text { officinalis }\end{array}$ & P6901/67 & JF950016 & 20.5 & 87.0 & ND & ND & ND & ND & ND & ND & ND \\
\hline Rubiaceae & Hedyotis diffusa & $\mathrm{P} 6874 / 40$ & JF949979 & 158.7 & 1542.7 & $>200$ & $>200$ & 5 & ++ & ++ & ++++ & 0 \\
\hline \multirow[t]{3}{*}{ Rutaceae } & Evodia lepta & P6869/35 & JF949978 & 419.2 & 971.0 & $>200$ & 20 & $>200$ & ++++ & 0 & ++++ & 0 \\
\hline & Evodia rutaecarpa & P6870/36 & - & 1176.9 & 185.6 & $>200$ & 25 & 100 & ++++ & ++ & 0 & ND \\
\hline & $\begin{array}{l}\text { Phellodendron } \\
\text { chinense }\end{array}$ & $\mathrm{P} 6890 / 56$ & JF949986 & 282.9 & 750.3 & 50 & 10 & 85 & ++ & ++ & ND & ND \\
\hline Saururaceae & Houttuynia cordata & $\mathrm{P} 6875 / 41$ & JF950006 & 633.2 & 2835.9 & $>200$ & 135 & 5 & 0 & ++ & 0 & ND \\
\hline Schisandraceae & $\begin{array}{l}\text { Kadsura } \\
\text { longipedunculata }\end{array}$ & $\mathrm{P} 6879 / 45$ & JF950007 & 6.8 & 167.6 & $>200$ & 20 & 20 & ++ & ++ & 0 & ND \\
\hline Selaginellaceae & $\begin{array}{l}\text { Selaginella } \\
\text { tamariscina }\end{array}$ & P6904/70 & JF950018 & 103.9 & 703.4 & $>200$ & $>200$ & 200 & 0 & ++ & 0 & 0 \\
\hline Valerianaceae & $\begin{array}{l}\text { Patrinia } \\
\text { scabiosaefolia } \\
\end{array}$ & P6889/55 & JF949985 & 147.3 & 525.5 & 168 & 87 & 35 & ++ & ++ & 0 & ND \\
\hline Verbenaceae & Verbena officinalis & P6910/76 & JF950020 & 93.9 & 416.9 & 100 & 168 & 117 & ++ & 0 & ND & ND \\
\hline Violaceae & Viola yezoensis & P6911/77 & JF949993 & 135.0 & 1459.2 & 170 & 200 & 140 & 0 & + & ND & ND \\
\hline \multirow[t]{2}{*}{ Zingiberaceae } & Alpinia galanga & P6837/03 & - & 952.8 & 2357.3 & $>200$ & $>200$ & $>200$ & 0 & ++ & ++ & ++ \\
\hline & Alpinia oxyphylla & P6917/78 & - & 105.8 & 1802.2 & $>200$ & $>200$ & 155 & 0 & ++ & 0 & ND \\
\hline
\end{tabular}

${ }^{a}$ Toxicity on EBTr cells: 0 , not toxic; ++ , toxic at high concentrations; ++++ , toxic in all concentrations; ${ }^{b}$ Anti-BVDV protection in EBTr cells: 0 , without effect; + , protection at high concentrations; ++, protection at low concentrations; ${ }^{c}$ Anti-HBV effect in HepG2 2.2.15 cells: 0 , without effect; ++, effect comparable to toxicity; ++++ , high ability to reduce HBV-DNA; ${ }^{d}$ Toxicity at effective dose on HepG2 2.2 .15 cells: 0 , not toxic; ++ , effect comparable to reduction in HBV DNA. ND: Not determined. 
Table 4. Cytotoxicity against HeLa cancer cells, Cos7 fibroblasts and Trypanosoma brucei brucei of organic extracts obtained from 82 medicinal plants.

\begin{tabular}{|c|c|c|c|c|c|c|c|c|c|c|c|c|c|}
\hline \multirow[b]{2}{*}{ Family } & \multirow[b]{2}{*}{ Species } & \multirow[b]{2}{*}{ IPMB/No. } & \multirow[b]{2}{*}{ GenBank } & \multirow{2}{*}{$\begin{array}{c}\mathrm{CH}_{2} \mathrm{Cl}_{2} \\
\text { HeLa }\end{array}$} & \multirow{2}{*}{$\begin{array}{c}\mathrm{CH}_{2} \mathrm{Cl}_{2} \\
\mathrm{Cos} 7\end{array}$} & \multirow{2}{*}{$\begin{array}{c}\mathrm{CH}_{2} \mathrm{Cl}_{2} \\
\text { T. b. } \\
\text { brucei } \\
\end{array}$} & \multirow{2}{*}{$\begin{array}{c}\text { Ratio } \\
\text { HeLa/T. } \\
\text { b. brucei }\end{array}$} & \multirow{2}{*}{$\begin{array}{c}\text { Ratio } \\
\text { Cos7/T. } \\
\text { b. brucei }\end{array}$} & \multirow{2}{*}{$\begin{array}{c}\text { MeOH } \\
\text { HeLa }\end{array}$} & \multirow{2}{*}{$\begin{array}{c}\text { MeOH } \\
\text { Cos } 7\end{array}$} & \multirow{2}{*}{$\begin{array}{c}\text { MeOH } \\
\text { T. b. } \\
\text { brucei }\end{array}$} & \multirow{2}{*}{$\begin{array}{c}\text { Ratio } \\
\text { HeLa/T. } \\
\text { b. brucei }\end{array}$} & \multirow{2}{*}{$\begin{array}{r}\text { Ratio } \\
\text { Cos7/T. } \\
\text { b. bruce }\end{array}$} \\
\hline & & & & & & & & & & & & & \\
\hline Acanthaceae & Andrographis paniculata & $\mathrm{P} 6838 / 04$ & JF949965 & 188.4 & 104.7 & 16.8 & 11 & 6 & 323.3 & 344.7 & 28.8 & 11 & 12 \\
\hline Amaranthaceae & Celosia cristata & P6848/14 & JF949970 & 472.0 & 136.0 & 55.2 & 9 & 2 & 499.8 & 28.4 & 77.2 & 6 & 0.3 \\
\hline \multirow[t]{5}{*}{ Apiaceae } & Bupleurum chinense & $\mathrm{P} 6844 / 10$ & JF950021 & 235.2 & 87.1 & 17.0 & 14 & 5 & 646.4 & 358.7 & 120.8 & 5 & 3 \\
\hline & Bupleurum marginatum & $\mathrm{P} 6845 / 11$ & JF949968 & 176.0 & 67.4 & 16.2 & 11 & 4 & 1147.0 & 576.0 & 111.9 & 10 & 5 \\
\hline & Centella asiatica & $\mathrm{P} 6849 / 15$ & JF950022 & 175.0 & 64.9 & 14.0 & 13 & 4 & 773.0 & 392.8 & 44.7 & 17 & 8 \\
\hline & Cnidium monnieri & $\mathrm{P} 6854 / 20$ & JF949973 & 127.1 & 37.0 & 14.9 & 9 & 2 & 251.1 & 120.0 & 17.9 & 14 & 6 \\
\hline & Saposhnikovia divaricata & $\mathrm{P} 6902 / 68$ & JF949988 & 410.1 & 45.9 & 5.1 & 80 & 9 & 1515.6 & 1575.4 & 999.5 & 2 & 1 \\
\hline \multirow[t]{3}{*}{ Araliaceae } & Eleutherococcus senticosus & P6919/79 & - & 300.0 & 61.4 & 13.5 & 22 & 4 & 692.0 & 190.1 & 17.3 & 40 & 11 \\
\hline & Panax ginseng & P8088/81 & JF950028 & 152.4 & 47.7 & 0.9 & 169 & 53 & 1427.9 & 510.8 & 319.0 & 4 & 1 \\
\hline & Panax notoginseng & P6887/53 & JF950030 & 263.0 & 6.4 & 0.9 & 292 & 7 & 1241.6 & 229.5 & 469.6 & 2 & 0.4 \\
\hline Arecaceae & Areca catechu & $\mathrm{P} 6840 / 06$ & - & 1023.3 & 117.0 & 22.5 & 45 & 5 & 414.2 & 31.0 & 118.1 & 4 & 0.2 \\
\hline Asclepiadaceae & Cynanchum paniculatum & $\mathrm{P} 6858 / 24$ & JF949975 & 395.6 & 114.2 & 53.1 & 7 & 2 & 500.5 & 227.7 & 39.3 & 13 & 5 \\
\hline \multirow[t]{10}{*}{ Asteraceae } & Artemisia annua & P6841/07 & JF949966 & 107.9 & 34.5 & 8.1 & 13 & 4 & 287.2 & 201.1 & 51.2 & 6 & 4 \\
\hline & Artemisia capillaris & $\mathrm{P} 6842 / 08$ & JF949967 & 93.5 & 29.4 & 10.6 & 9 & 3 & 314.9 & 215.4 & 51.9 & 6 & 4 \\
\hline & Arctium lappa & $\mathrm{P} 6839 / 05$ & JF949994 & 345.0 & 344.2 & 3.6 & 96 & 96 & 1467.7 & 1813.0 & 2229.0 & 0.7 & 0.8 \\
\hline & Centipeda minima & $\mathrm{P} 6850 / 16$ & - & 63.3 & 10.4 & 2.2 & 29 & 5 & 219.1 & 54.2 & 13.3 & 16 & 4.0 \\
\hline & Chrysanthemum indicum & P6851/17 & JF949971 & 152.1 & 63.5 & 16.0 & 10 & 4 & 355.7 & 287.2 & 15.3 & 23 & 18 \\
\hline & Chrysanthemum morifolium & P6852/18 & JF949972 & 129.4 & 42.8 & 19.3 & 7 & 2 & 349.2 & 166.7 & 24.9 & 14 & 6 \\
\hline & Eclipta prostata & P6863/29 & JF950000 & 266.4 & 112.0 & 38.1 & 7 & 3 & 329.7 & 186.1 & 39.6 & 8 & 4.6 \\
\hline & Senecio scandens & P6905/71 & JF949989 & 268.6 & 143.5 & 13.1 & 21 & 11 & 299.3 & 126.2 & 18.6 & 16 & 6 \\
\hline & Siegesbeckia orientalis & P6906/72 & JF949990 & 101.5 & 17.7 & 7.9 & 13 & 2 & 237.5 & 84.4 & 12.3 & 19 & 6 \\
\hline & Taraxacum officinale & P6908/74 & JF950019 & 232.8 & 177.1 & 17.5 & 13 & 10 & 636.7 & 485.3 & 64.9 & 10 & 7 \\
\hline
\end{tabular}


Table 4. Cont.

\begin{tabular}{|c|c|c|c|c|c|c|c|c|c|c|c|c|c|}
\hline \multirow[b]{2}{*}{ Family } & \multirow[b]{2}{*}{ Species } & \multirow[b]{2}{*}{ IPMB/No. } & \multirow[b]{2}{*}{ GenBank } & \multirow{2}{*}{$\begin{array}{c}\mathrm{CH}_{2} \mathrm{Cl}_{2} \\
\mathrm{HeLa}\end{array}$} & \multirow{2}{*}{$\begin{array}{c}\mathrm{CH}_{2} \mathrm{Cl}_{2} \\
\mathrm{Cos} 7\end{array}$} & \multirow{2}{*}{$\begin{array}{c}\mathrm{CH}_{2} \mathrm{Cl}_{2} \\
\text { T. b. } \\
\text { brucei }\end{array}$} & \multirow{2}{*}{$\begin{array}{c}\text { Ratio } \\
\text { HeLa/T. } \\
\text { b. brucei }\end{array}$} & \multirow{2}{*}{$\begin{array}{c}\text { Ratio } \\
\text { Cos7/T. } \\
\text { b. brucei }\end{array}$} & \multirow{2}{*}{$\begin{array}{l}\text { MeOH } \\
\text { HeLa }\end{array}$} & \multirow{2}{*}{$\begin{array}{c}\text { MeOH } \\
\text { Cos } 7\end{array}$} & \multirow{2}{*}{$\begin{array}{c}\text { MeOH } \\
\begin{array}{c}\text { T. } b . \\
\text { brucei }\end{array} \\
\end{array}$} & \multirow{2}{*}{$\begin{array}{c}\text { Ratio } \\
\text { HeLa/T. } \\
\text { b. brucei }\end{array}$} & \multirow{2}{*}{\begin{tabular}{l}
\multicolumn{1}{c}{ Ratio } \\
Cos7/T. b. \\
brucei
\end{tabular}} \\
\hline & & & & & & & & & & & & & \\
\hline \multirow[t]{3}{*}{ Berberidaceae } & Berberis bealei & P6883/49 & JF949996 & 93.8 & 13.3 & 5.9 & 16 & 2 & 149.7 & 35.3 & 7.8 & 19 & 4 \\
\hline & Dysosma versipellis & P6862/28 & - & 213.9 & 49.9 & 39.5 & 5 & 1 & 385.2 & 54.9 & 53.2 & 7 & 1.0 \\
\hline & Epimedium koreanum & P6865/31 & JF950002 & 48.7 & 3.5 & 4.2 & 12 & 0.8 & 257.5 & 30.7 & 12.6 & 20 & 2 \\
\hline \multirow[t]{2}{*}{ Brassicaceae } & Isatis indigotica (root) & P6877/43 & JF949981 & 196.4 & 42.3 & 2.9 & 68 & 14 & 674.3 & 324.4 & 94.6 & 7 & 3 \\
\hline & Isatis indigotica (leaf) & P6878/44 & JF949981 & 321.5 & 0.6 & 45.3 & 7 & 0.01 & 274.2 & 90.6 & 14.6 & 19 & 6 \\
\hline Caprifoliaceae & Lonicera confusa & P6880/46 & JF949982 & 226.5 & 58.9 & 16.2 & 14 & 3 & 923.5 & 118.9 & 38.0 & 24 & 3 \\
\hline Convallariaceae & Polygonatum kingianum & P6892/58 & JF950027 & 279.6 & 53.9 & 52.6 & 5 & 1 & 1517.9 & 1535.3 & 119.5 & 13 & 12 \\
\hline Crassulaceae & Rhodiola rosea & P6920/84 & - & 164.1 & 74.6 & 43.9 & 4 & 1 & - & 87.4 & - & - & - \\
\hline Cupressaceae & Platycladus orientalis & P6891/57 & JF950011 & 121.7 & 21.8 & 17.7 & 7 & 1 & 705.5 & 158.2 & 84.2 & 8 & 1 \\
\hline Dryopteridaceae & Cyrtomium fortunei & P6859/25 & JF949998 & 572.4 & 132.1 & 37.1 & 15 & 3 & 722.0 & 348.7 & 61.0 & 12 & 5 \\
\hline Ephedraceae & Ephedra sinica & P6864/30 & JF950001 & 95.3 & 41.8 & 20.9 & 5 & 2 & 163.5 & 36.7 & 23.4 & 7 & 1 \\
\hline Equisetaceae & Equisetum hiemale & P6866/32 & JF950003 & 125.6 & 35.7 & 30.9 & 4 & 1 & 241.2 & 243.5 & 51.6 & 4 & 4 \\
\hline Euphorbiaceae & Croton tiglium & P6856/22 & - & 422.9 & 225.9 & 86.5 & 5 & 2 & 297.0 & 222.1 & 150.4 & 2 & 1 \\
\hline \multirow[t]{7}{*}{ Fabaceae } & Abrus cantoniensis & $\mathrm{P} 6835 / 01$ & JF949964 & 494.4 & 129.4 & 14.5 & 34 & 9 & 612.4 & 733.1 & 73.5 & 8 & 10 \\
\hline & Acacia catechu & P6836/02 & - & 164.1 & 31.5 & 13.1 & 12 & 2 & 318.0 & 34.8 & 50.8 & 6 & 0.6 \\
\hline & Cassia tora & P6847/13 & JF949969 & 1335.4 & 189.1 & 185.9 & 7 & 1 & 670.9 & 75.9 & 276.9 & 2 & 0.2 \\
\hline & Desmodium styracifolium & P6861/27 & JF949976 & 156.0 & 139.8 & 16.3 & 10 & 8 & 324.3 & 104.1 & 40.1 & 8 & 2 \\
\hline & Glycyrrhiza inflata & P6873/39 & JF950025 & 26.4 & 6.9 & 6.4 & 4 & 1 & 528.3 & 126.8 & 39.0 & 14 & 3 \\
\hline & Spatholobus suberectus & P6907/73 & JF949991 & 299.1 & 154.6 & 25.4 & 12 & 6 & 237.5 & 54.8 & 67.8 & 4 & 0.8 \\
\hline & Sutherlandia frutescens & $\mathrm{tba} / 83$ & - & 367.7 & 259.3 & 41.8 & 9 & 6 & 586.6 & 352.0 & 87.4 & 7 & 4 \\
\hline \multirow[t]{2}{*}{ Geraniaceae } & Geranium wilfordii & P6867/33 & JF949977 & 99.1 & 17.0 & 23.0 & 4 & 0.7 & 236.0 & 169.8 & 13.3 & 18 & 12 \\
\hline & Pelargonium sidoides & tba/ 82 & - & 488.2 & 218.2 & 52.1 & 9 & 4 & 112.3 & 95.7 & 18.3 & 6 & 5 \\
\hline Ginkgoaceae & Ginkgo biloba & $\mathrm{P} 6872 / 38$ & JF950005 & 768.3 & 15.3 & 71.9 & 11 & 0.2 & 302.9 & 260.1 & 39.3 & 8 & 6 \\
\hline Hypericaceae & Hypericum japonicum & P6876/42 & JF949980 & 163.3 & 10.8 & 21.3 & 8 & 0.5 & 177.5 & 100.9 & 23.6 & 8 & 4 \\
\hline
\end{tabular}


Table 4. Cont.

\begin{tabular}{|c|c|c|c|c|c|c|c|c|c|c|c|c|c|}
\hline \multirow[b]{2}{*}{ Family } & \multirow[b]{2}{*}{ Species } & \multirow[b]{2}{*}{ IPMB/No. } & \multirow[b]{2}{*}{ GenBank } & \multirow{2}{*}{$\begin{array}{c}\mathrm{CH}_{2} \mathrm{Cl}_{2} \\
\text { HeLa }\end{array}$} & \multirow{2}{*}{$\begin{array}{c}\mathrm{CH}_{2} \mathrm{Cl}_{2} \\
\mathrm{Cos} 7\end{array}$} & \multirow{2}{*}{$\begin{array}{c}\mathrm{CH}_{2} \mathrm{Cl}_{2} \\
\text { T. b. } \\
\text { brucei } \\
\end{array}$} & \multirow{2}{*}{$\begin{array}{c}\text { Ratio } \\
\text { HeLa/T. } \\
\text { b. brucei }\end{array}$} & \multirow{2}{*}{$\begin{array}{c}\text { Ratio } \\
\text { Cos7/T. } \\
\text { b. brucei }\end{array}$} & \multirow{2}{*}{$\begin{array}{c}\text { MeOH } \\
\text { HeLa }\end{array}$} & \multirow{2}{*}{$\begin{array}{c}\text { MeOH } \\
\text { Cos } 7\end{array}$} & \multirow{2}{*}{$\begin{array}{c}\text { MeOH } \\
\text { T. b. } \\
\text { brucei }\end{array}$} & \multirow{2}{*}{$\begin{array}{c}\text { Ratio } \\
\text { HeLa/T. } \\
\text { b. brucei }\end{array}$} & \multirow{2}{*}{\begin{tabular}{l}
\multicolumn{1}{c}{ Ratio } \\
Cos7/T. b \\
brucei
\end{tabular}} \\
\hline & & & & & & & & & & & & & \\
\hline Iridaceae & Belamcanda chinensis & P6843/09 & JF949995 & 324.4 & 89.2 & 22.3 & 15 & 4 & 522.6 & 319.5 & 80.2 & 7 & 4 \\
\hline \multirow[t]{3}{*}{ Lamiaceae } & Mentha haplocalyx & $\mathrm{P} 6884 / 50$ & JF949984 & 108.5 & 34.1 & 14.7 & 7 & 2 & 375.0 & 147.8 & 16.2 & 23 & 9 \\
\hline & Prunella vulgaris & P6896/62 & JF950013 & 282.1 & 90.4 & 13.2 & 21 & 7 & 475.4 & 494.5 & 25.1 & 19 & 19 \\
\hline & Scutellaria baicalensis & P6903/69 & JF950017 & 90.9 & 287.9 & 7.4 & 12 & 39 & 367.6 & 28.8 & 86.2 & 4 & 0.3 \\
\hline Lauraceae & Cinnamomum cassia & P6853/19 & JF950023 & 138.9 & 23.2 & 11.0 & 13 & 2 & 272.4 & 108.4 & 13.4 & 20 & 8 \\
\hline Loranthaceae & Taxillus chinensis & P6909/75 & JF949992 & 417.8 & 68.6 & 27.2 & 15 & 2 & 1213.4 & 378.2 & 59.2 & 20 & 6 \\
\hline Lythraceae & Punica granatum & P6897/63 & JF950014 & 583.3 & 126.6 & 14.6 & 40 & 8 & 211.2 & 218.6 & 8.1 & 26 & 27 \\
\hline Magnoliaceae & Magnolia officinalis & P6882/48 & JF950008 & 23.6 & 5.4 & 0.9 & 26 & 6 & 49.1 & 13.1 & 4.3 & 11 & 3 \\
\hline Melanthiaceae & Paris polyphylla & P6888/54 & JF950010 & 952.6 & 24.0 & 73.6 & 13 & 0.3 & 35.0 & 5.5 & 11.8 & 3 & 0.4 \\
\hline Myrsinaceae & Lysimachia christinae & P6881/47 & JF949983 & 53.4 & 137.3 & 20.6 & 3 & 7 & 1752.6 & 436.3 & 52.1 & 34 & 8 \\
\hline Myrtaceae & Eucalyptus robusta & P6868/34 & - & - & - & - & & & 181.4 & 15.2 & 16.3 & 11 & 1 \\
\hline Ophioglossaceae & Ophioglossum vulgatum & $\mathrm{P} 6885 / 51$ & JF950009 & 188.9 & 62.8 & 19.8 & 10 & 3 & 469.0 & 68.8 & 33.2 & 14 & 2 \\
\hline Orchidaceae & Dendrobium loddigesii & P6860/26 & JF949999 & 83.0 & 25.7 & 13.5 & 6 & 2 & 232.8 & 61.6 & 27.6 & 8 & 2 \\
\hline Paeoniaceae & Paeonia lactiflora & P6886/52 & JF950026 & 166.9 & 34.0 & 9.1 & 18 & 3 & 294.6 & 309.8 & 11.7 & 25 & 26 \\
\hline Pedaliaceae & $\begin{array}{l}\text { Harpagophytum } \\
\text { procumbens }\end{array}$ & $\mathrm{tba} / 80$ & - & 36.2 & 15.8 & 0.9 & 40 & 17 & 692.6 & 217.2 & 21.4 & 32 & 10 \\
\hline Poaceae & Cymbopogon distans & P6857/23 & JF949974 & 425.9 & 114.5 & 31.1 & 14 & 3 & 98.8 & 17.6 & 18.9 & 5 & 1 \\
\hline \multirow[t]{4}{*}{ Polygonaceae } & Fallopia japonica & P6894/60 & JF950004 & 88.0 & 2.8 & 13.1 & 7 & 0.2 & 317.3 & 19.5 & 19.0 & 17 & 1 \\
\hline & Polygonum aviculare & P6893/59 & JF950012 & 118.5 & 53.3 & 18.2 & 7 & 3 & 342.3 & 226.5 & 49.1 & 7 & 4 \\
\hline & Polygonum multiflorum & P6895/61 & JF949987 & 469.4 & 107.7 & 98.6 & 5 & 1 & 437.4 & 48.8 & 62.1 & 7 & 0.7 \\
\hline & Rheum officinale & P6898/64 & JF950015 & 22.5 & - & 34.0 & 0.6 & - & 270.9 & 35.3 & 24.5 & 11 & 1 \\
\hline Ranunculaceae & Coptis chinensis & P6855/21 & JF950024 & 100.0 & 39.5 & 12.9 & 8 & 3 & 81.8 & 3.7 & 0.4 & 205 & 9 \\
\hline
\end{tabular}


Table 4. Cont.

\begin{tabular}{|c|c|c|c|c|c|c|c|c|c|c|c|c|c|}
\hline \multirow[b]{2}{*}{ Family } & \multirow[b]{2}{*}{ Species } & \multirow[b]{2}{*}{ IPMB/No. } & \multirow[b]{2}{*}{ GenBank } & \multirow{2}{*}{$\begin{array}{c}\mathrm{CH}_{2} \mathrm{Cl}_{2} \\
\mathrm{HeLa}\end{array}$} & \multirow{2}{*}{$\frac{\mathrm{CH}_{2} \mathrm{Cl}_{2}}{\operatorname{Cos} 7}$} & \multirow{2}{*}{$\begin{array}{c}\mathrm{CH}_{2} \mathrm{Cl}_{2} \\
\text { T. b. } \\
\text { brucei }\end{array}$} & \multirow{2}{*}{$\begin{array}{c}\text { Ratio } \\
\text { HeLa/T. } \\
\text { b. brucei }\end{array}$} & \multirow{2}{*}{$\begin{array}{c}\text { Ratio } \\
\text { Cos7/T. } \\
\text { b. brucei } \\
\end{array}$} & \multirow{2}{*}{$\begin{array}{c}\text { MeOH } \\
\text { HeLa }\end{array}$} & \multirow{2}{*}{$\begin{array}{c}\text { MeOH } \\
\text { Cos } 7\end{array}$} & \multirow{2}{*}{$\begin{array}{c}\text { MeOH } \\
\text { T. b. } \\
\text { brucei }\end{array}$} & \multirow{2}{*}{$\begin{array}{c}\text { Ratio } \\
\text { HeLa/T. } \\
\text { b. brucei } \\
\end{array}$} & \multirow{2}{*}{\begin{tabular}{l}
\multicolumn{1}{c}{ Ratio } \\
Cos7/T. b. \\
brucei
\end{tabular}} \\
\hline & & & & & & & & & & & & & \\
\hline \multirow[t]{3}{*}{ Rosaceae } & Rosa chinensis & P6899/65 & - & 559.4 & 141.5 & 20.1 & 28 & 7 & 266.6 & 36.7 & 12.5 & 21 & 3 \\
\hline & Rosa laevigata & P6900/66 & - & 712.3 & 151.8 & 20.6 & 35 & 7 & 1855.4 & 1100.1 & 102.9 & 18 & 10 \\
\hline & Sanguisorba officinalis & P6901/67 & JF950016 & 66.5 & 26.7 & 12.3 & 5 & 2 & 158.5 & 41.6 & 4.0 & 40 & 10 \\
\hline Rubiaceae & Hedyotis diffusa & $\mathrm{P} 6874 / 40$ & JF949979 & 147.8 & 45.3 & 13.3 & 11 & 3 & 796.1 & 418.1 & 24.9 & 32 & 16 \\
\hline \multirow[t]{3}{*}{ Rutaceae } & Evodia lepta & $\mathrm{P} 6869 / 35$ & JF949978 & 232.0 & 42.0 & 13.9 & 17 & 3 & 350.7 & 427.7 & 44.4 & 8 & 9 \\
\hline & Evodia rutaecarpa & P6870/36 & - & 50.4 & 8.7 & 16.8 & 3 & 0.5 & 297.4 & 178.5 & 29.5 & 10 & 6 \\
\hline & Phellodendron chinense & P6890/56 & JF949986 & 370.1 & 71.3 & 15.6 & 24 & 4 & 487.6 & 85.5 & 14.1 & 35 & 6 \\
\hline Saururaceae & Houttuynia cordata & $\mathrm{P} 6875 / 41$ & JF950006 & 279.9 & 48.2 & 68.3 & 4 & 0.7 & 575.2 & 63.9 & 97.6 & 6 & 0.6 \\
\hline Schisandraceae & Kadsura longipedunculata & $\mathrm{P} 6879 / 45$ & JF950007 & 9.9 & 1.8 & 0.1 & 99 & 18 & 86.1 & 43.9 & 11.8 & 7 & 3 \\
\hline Selaginellaceae & Selaginella tamariscina & P6904/70 & JF950018 & 339.2 & 98.8 & 13.6 & 25 & 7 & 393.9 & 150.9 & 33.4 & 12 & 4 \\
\hline Valerianaceae & Patrinia scabiosaefolia & $\mathrm{P} 6889 / 55$ & JF949985 & 140.5 & 38.7 & 13.7 & 10 & 3 & 159.4 & 15.9 & 19.0 & 8 & 0.8 \\
\hline Verbenaceae & Verbena officinalis & P6910/76 & JF950020 & 298.1 & 145.9 & 16.5 & 18 & 9 & 334.7 & 37.7 & 20.5 & 16 & 1 \\
\hline Violaceae & Viola yezoensis & P6911/77 & JF949993 & 59.6 & 60.8 & 3.3 & 18 & 18 & 297.5 & 19.1 & 24.7 & 12 & 0.7 \\
\hline \multirow[t]{2}{*}{ Zingiberaceae } & Alpinia galanga & P6837/03 & - & 55.7 & 5.7 & 1.4 & 39 & 4 & 111.7 & 53.4 & 15.4 & 7 & 3 \\
\hline & Alpinia oxyphylla & P6917/78 & - & 119.6 & 30.4 & 0.7 & 170 & 43 & 213.8 & 110.2 & 2.0 & 107 & 55 \\
\hline
\end{tabular}


Quercetin 3-O-methyl ether and ophioglonin obtained from plants belonging to Ophioglossaceae genus have shown slight activity against HBV [50]. Since 1995 when antiviral activities against enveloped viruses were discovered in extracts of Houttuynia cordata [51], such as influenza, HIV, herpes, SARS and also in enteroviruses [51-54], 40 compounds have been isolated from the whole plant [55].

Among all of them, norcepharadione B has been identified as anti-herpes virus type 1 compound [55], quercetin may reduce virions production of $\mathrm{HCV}$ [56], but not against $\mathrm{HBV}$ [7] and quercetin 3-rhamnoside may be effective against influenza A virus [57].

Selaginella tamariscina has been a source of several drugs with anti-bacterial and antifungal activities such as amentoflavone [58], isocryptomerin [59-61], or with antitumor effects such as sterols [62] and biflavonoids [63]. Alpinia galanga crude extracts have been shown to have antibacterial activities [64] which seem to be enhanced in combination with other plants such as rosemary and lemon iron bark [65]. Compounds obtained from this plant, have also demonstrated other antimicrobial activities, such as anti-leishmanial phenylpropanoids [66] or 1'-acetoxychavicol acetate, and its halogenated derivatives (inhibitors of HIV-regulator protein Rev-export) [67-70].

The insecticidal properties of diarylheptanoid [71] as well as protective effects on anaphylactic reactions of the aqueous extracts from the fruit of Alpinia oxyphylla [72] have been described in the past. Recently anti-angiogenic properties of the fruit have been also discovered [73].

The water extracts were also screened against HBV in HepG2 2.2.15 cells (Table 3). Evodia lepta, Hedyotis diffusa and several Glycyrrhiza species lowered the HBV-DNA significantly and were not toxic to the HepG2 2.2.15 cell line (Figure 1).

Hardly anything is known about the other natural products of Evodia lepta, while the highly bioactive chromenes seem to be among the major constituents [74]. Glycyrrhiza species, on the other hand, are well known for their anti-inflammatory effects due to glycyrrhizic acid [9]. This genus is also known for its antiviral, especially antihepatitis properties [15,75]. Its ability to reduce the HBVDNA in the culture medium of HepG2 2.2.15 at high doses has been previously reported [7]. Heydiotis diffusa again is a plant rich in iridoid glycosides with anti-inflammatory and hepatoprotective activities [76-78]. These compounds are most likely to be responsible for the effects against HBV.

Three enterohepatic cancer cell lines, HepG2 and SK-Hep1 (from human hepatoblastoma and hepatocarcinoma) and LS 174T (from human colon adenocarcinoma), were used to determine the antitumor ability of water extracts (Table 3). Twenty extracts were found to induce a significant antiproliferative effect with $\mathrm{IC}_{50}$ values between 0.5 and $20 \mu \mathrm{g} / \mathrm{mL}$ on these cell lines. These were further investigated to elucidate whether this was due to cytotoxicity.

In HepG2, none of the 4 extracts with ability to inhibit cell growth (Coptis chinensis, Epimedium brevicornum, Equisetum hiemale and Senecio scandens), were found to induce acute cell toxicity when they were incubated with the $\mathrm{IC}_{50}$ of the extracts for $6 \mathrm{~h}$ (Figure 2).

In SK-Hep1, among the 10 extracts with antitumor effect 7 did not induce acute toxicity (Arctium lappa, Cassia tora, Centipeda minima, Chrysanthemum indicum, Coptis chinensis, Phellodendron chinense and Rheum palmatum), whereas Dysosma versipellis was especially active by lowering the cell viability in comparison to the control to $40 \%$ (Figure 3 ). This is consistent with the inhibitory effects known for the lignans of $D$. versipellis against prostate cancer cell lines [79]. 
Figure 1. Effect of water extracts on hepatitis B virus (HBV) release as determined by HBV-DNA content in the culture medium and cell viability as determined by Neutral Red uptake by human hepatoblastoma cells HepG2 2.2.15 infected with HBV. Values are means $\pm \mathrm{SD}$ of three experiments carried out in triplicate by incubation with the extracts for 21 days. ${ }^{*}, \mathrm{p}<0.05$ as compared with untreated cells by paired $t$-test.
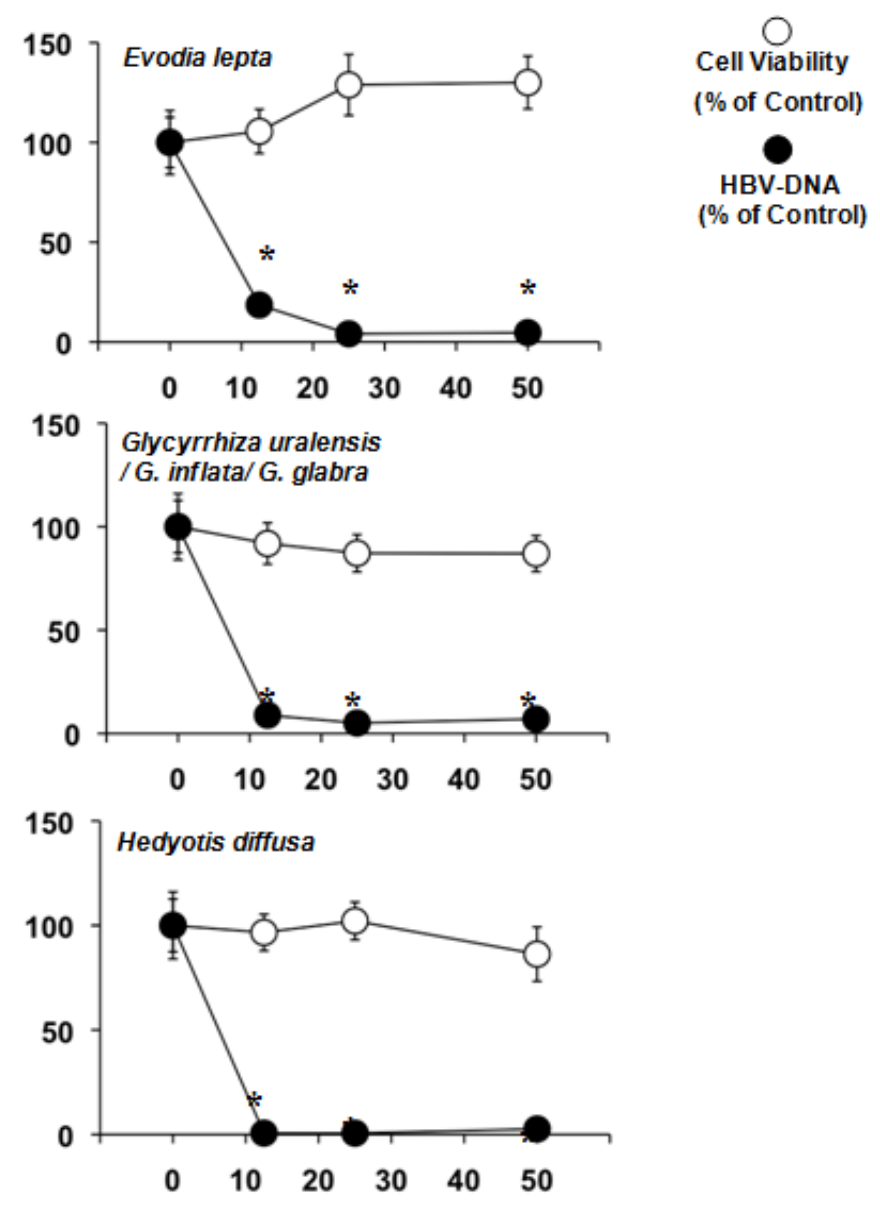

Figure 2. Acute cell toxicity as determined by 3-(4,5-dimethylthiazol-2-yl)-2, 5-difenyltetrazolium (MTT) assay in human hepatoblastoma HepG2 cells. Values are means $\pm \mathrm{SD}$ of four experiments carried out in triplicate.

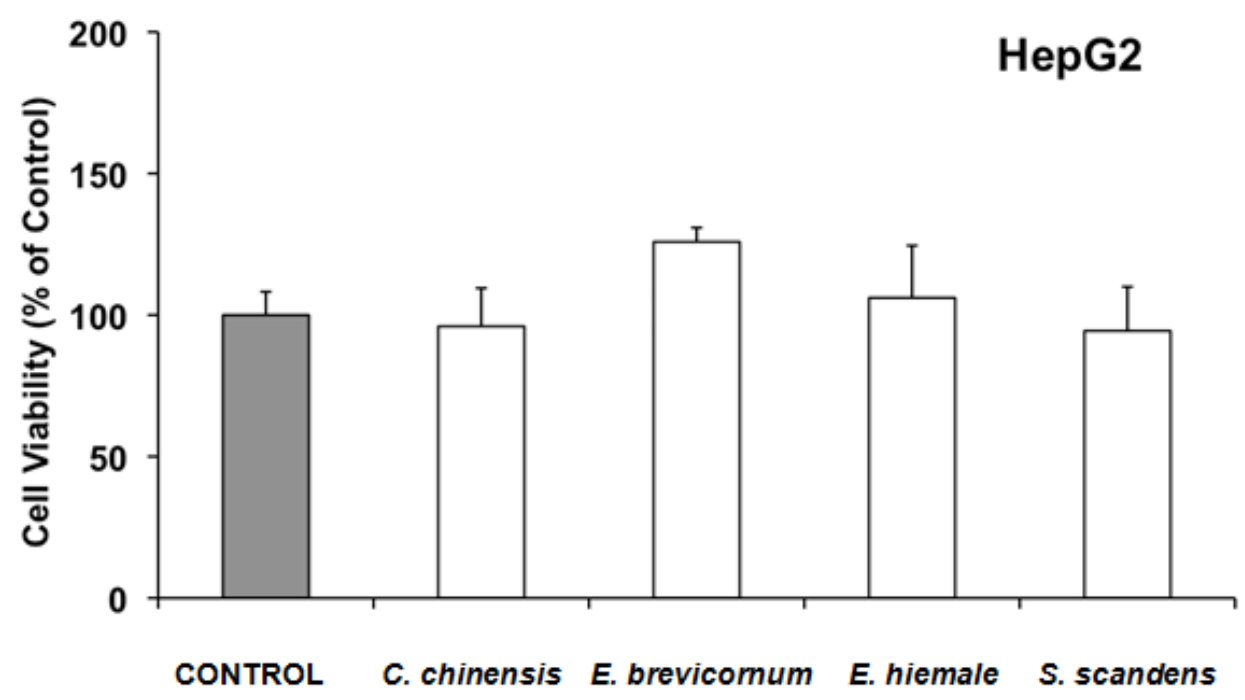


Figure 3. Acute cell toxicity as determined by MTT assay in human hepatoma SK-Hep1 cells. Values are means $\pm \mathrm{SD}$ of four experiments carried out in triplicate. ${ }^{*}, \mathrm{p}<0.05$ as compared with Control by the Bonferroni method of multiple range testing.

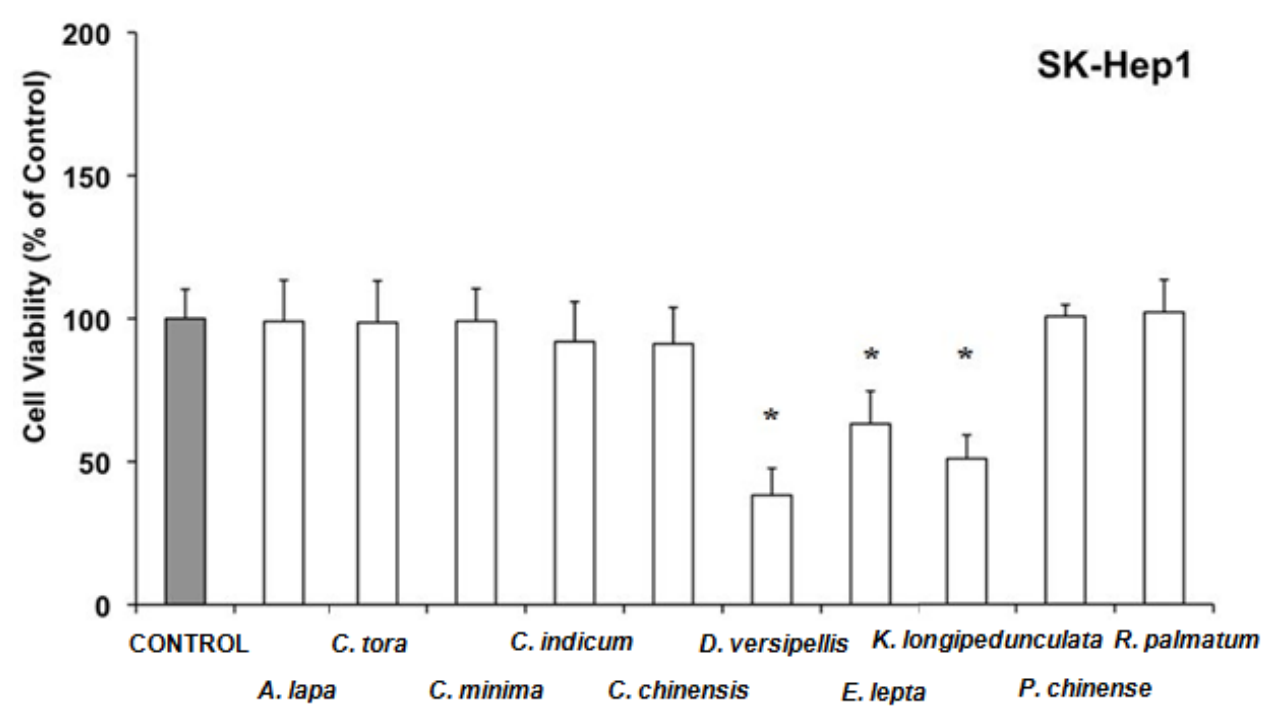

Evodia lepta and Kadsura longipedunculata lowered also the cell viability of SK-Hep1 in comparison to the control to 50-60\%. Recently, it has been reported that the essential oil of Kadsura longipedunculata and its major components (delta-cadinene, camphene, borneol, cubenol, and delta-cadinol) have some degree of cytotoxic activity against some human cell lines [80]. In LS 174T cells, water extracts from Coptis chinensis, Dysosma versipellis, Epimedium brevicornum, Hedyotis diffusa and Houttuynia cordata have antiproliferative effects without affecting cell viability (Figure 4), whereas Paeonia lactiflora, Platycladus orientalis, and Polygonum aviculare, in addition to inhibition of cell growth were able to acutely lower cell viability in comparison to the control to $60-70 \%$.

Figure 4. Acute cell toxicity as determined by MTT assay in human colon adenocarcinoma LS 174T cells. Values are means \pm SD of four experiments carried out in triplicate. *, $\mathrm{p}<0.05$ as compared with Control by the Bonferroni method of multiple range testing.

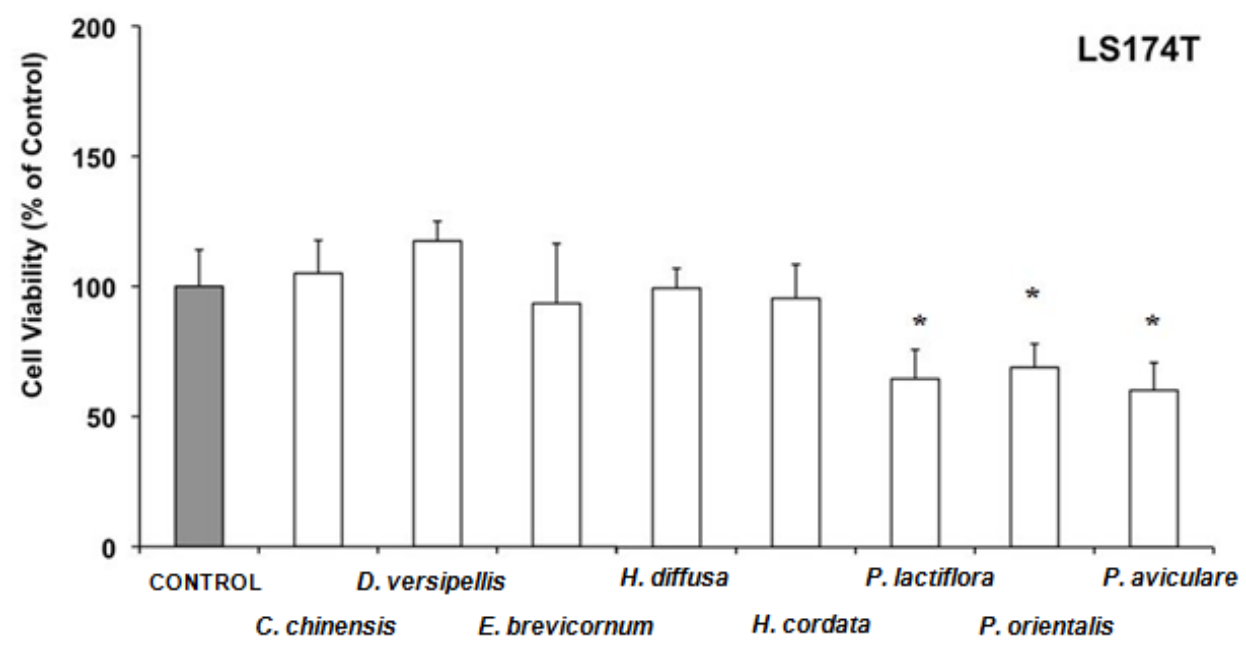


Paeonia lactiflora, which belongs to the Paeoniaceae family, is known as one of the richest sources of various resveratrol derivatives [81]. These phytoestrogens are known to exert strong antioxidant activity [81] and to inhibit growth of several cancer cell lines [82,83], including a colon human cell line [84]. Recently, the antiproliferative effects of essential oils obtained from Platycladus orientalis on human renal adenocarcinoma and amelanotic melanoma cells have been reported [85].

Coptis chinensis, which has been found active against the three enterohepatic cell lines, belongs to TCM formulations commonly used to treat liver diseases associated to infections by gastrointestinal parasite such as Blastocystis hominis [86]. Coptisine, which is used as gastric mucosa protector, and berberine, which has very interesting properties as antiinflamatory, antidiabetes, antidiarrhea, and hypocholesterolemic drug, have been obtained from this plant. Both of them have also shown antitumoral activities in in vitro models [87-92].

Animal cells offer several targets to natural products (Table 1). Of great importance are the biomembrane, the proteins and the DNA. Since human cells and trypanosomes share many similarities in the structure of the cells, it is extremely important to select those plant extracts where a great selectivity index (SI) occurred. The different cytotoxicity strongly hints to selective interactions between natural products and trypanosomes that do not occur in human cells. A great SI also hints to the relative absence or relative insignificance of general cytotoxic mechanisms like the unspecific interaction of phenolic OH-groups compared to more specific interactions with certain structures in trypanosomes.

The $\mathrm{CH}_{2} \mathrm{Cl}_{2}$ and $\mathrm{MeOH}$ extracts of 82 medicinal plants were screened against the cell lines HeLa, Cos7 and trypanosomes (T. b. brucei) (Table 4). The SI of the $\mathrm{IC}_{50}$ of mammalian cell/trypanosomes was regarded as significant if it was over 80 . According to this criterium, seven extracts were highly selective towards trypanosomes.

The $\mathrm{CH}_{2} \mathrm{Cl}_{2}$ extract of Alpinia oxyphylla showed $\mathrm{IC}_{50}$ values of $119.6 \mu \mathrm{g} / \mathrm{mL}, 30.4 \mu \mathrm{g} / \mathrm{mL}$ and $0.7 \mu \mathrm{g} / \mathrm{mL}$ against HeLa, Cos7 and T. b. brucei respectively with SI of 170 and 43 between HeLa and T. b. brucei and Cos7 and T. b. brucei respectively. The $\mathrm{MeOH}$ extract of A. oxyphylla also was effective with $\mathrm{IC}_{50}$ values of $213.8 \mu \mathrm{g} / \mathrm{mL}, 110.2 \mu \mathrm{g} / \mathrm{mL}$ and $2.0 \mu \mathrm{g} / \mathrm{mL}$ against HeLa, Cos7 and T. b. brucei respectively. The SI was 107 and 55 between HeLa and T. b. brucei and Cos7 and T. b. brucei respectively. A. oxyphylla is basically an essential oil plant, so that we suspect the active principle to be based on the sesquiterpenes already known for their cytotoxic properties [93].

For Kadsura longipedunculata only the $\mathrm{CH}_{2} \mathrm{Cl}_{2}$ extract exhibited a significant selectivity. Here, the $\mathrm{IC}_{50}$ values of HeLa, Cos7 and T. b. brucei were $9.9 \mu \mathrm{g} / \mathrm{mL}, 1.8 \mu \mathrm{g} / \mathrm{mL}$ and $0.1 \mu \mathrm{g} / \mathrm{mL}$ respectively, resulting in SI of 99 and 18 between HeLa and T. b. brucei and Cos7 and T. b. brucei respectively. Essential oil and lignans form the major natural compounds of $K$. longipedunculata [80,94]. The specific trypanocidal effect rather seems to be based on the lignans than on the more unspecific essential oil. Further studies would be necessary to confirm this assumption.

For Arctium lappa only the $\mathrm{CH}_{2} \mathrm{Cl}_{2}$ extract showed a significant selectivity with $\mathrm{IC}_{50}$ values of $345.0 \mu \mathrm{g} / \mathrm{mL}, 344.2 \mu \mathrm{g} / \mathrm{mL}$ and $3.6 \mu \mathrm{g} / \mathrm{mL}$ against HeLa, Cos7 and T. b. brucei respectively and SI of 96 between HeLa and T. b. brucei and Cos7 and T. b. brucei.

In Panax ginseng and $P$. notoginseng the selectivity was again limited to the $\mathrm{CH}_{2} \mathrm{Cl}_{2}$ extract. P. ginseng gave $\mathrm{IC}_{50}$ values of $152.4 \mu \mathrm{g} / \mathrm{mL}, 47.7 \mu \mathrm{g} / \mathrm{mL}$ and $0.9 \mu \mathrm{g} / \mathrm{mL}$ against HeLa, Cos 7 and T. b. brucei respectively with SI of 169 and 53 between HeLa and T. b. brucei and Cos7 and 
T. b. brucei respectively. $P$. notoginseng demonstrated $\mathrm{IC}_{50}$ values of $263.0 \mu \mathrm{g} / \mathrm{mL}, 6.4 \mu \mathrm{g} / \mathrm{mL}$ and $0.9 \mu \mathrm{g} / \mathrm{mL}$ with SI of 292 and 7 between HeLa and T. b. brucei and Cos 7 and T. b. brucei respectively.

Also an extremely active plant was Saposhnikovia divaricata. Here as well, lipophilic $\mathrm{CH}_{2} \mathrm{Cl}_{2}$ extract was selective with $\mathrm{IC}_{50}$ values of $410.1 \mu \mathrm{g} / \mathrm{mL}, 45.9 \mu \mathrm{g} / \mathrm{mL}$ and $5.1 \mu \mathrm{g} / \mathrm{mL}$ against HeLa, Cos7 and T. b. brucei respectively and SI of 80 and 9 between HeLa and T. b. brucei and Cos7 and T. b. brucei respectively.

The trypanocidal effects of A. lappa, P. ginseng, $P$. notoginseng and S. divaricata are based on the presence of highly reactive polyacetylenes, especially panaxynol.

Only the methanolic extract of Coptis chinensis showed a significant selectivity, but not the dichloromethane extract. The $\mathrm{IC}_{50}$ values of $81.8 \mu \mathrm{g} / \mathrm{mL}, 3.7 \mu \mathrm{g} / \mathrm{mL}$ and $0.4 \mu \mathrm{g} / \mathrm{mL}$ against HeLa, Cos7 and T. b. brucei respectively gave SI of 205 and 9 between HeLa and T. b. brucei and Cos7 and T. b. brucei respectively. Our analytical data confirmed berberine as the main alkaloid of C. chinensis. The toxicity of $C$. chinensis is probably an effect of the DNA intercalation of its alkaloids into the DNA double helix of T. b. brucei $[95,96]$.

The trypanocidal effect of berberine against different trypanosoma species has been demonstrated previously. Merschjohann et al. [97] showed that T. congolense are sensitive to berberine at concentrations of $83 \mu \mathrm{M}$, while Rosenkranz and Wink [98] demonstrated a sensitivity of T. brucei to berberine at concentrations of only $0.5 \mu \mathrm{M}$. Recently, the effect of berberine against $T$. rhodesiense was also established by Freiburghaus et al. [99]. T. rhodesiense was sensitive to $4.2 \mu \mathrm{g} / \mathrm{mL}$.

The significant differences in sensitivity of different trypanosoma species to berberine could be of high interest regarding resistance mechanisms against mutagenic compounds. Berberine might due to its mutagenic activity never become a lead structure for the development of trypanocidal drugs, but the differences in sensitivity of these three trypanosoma species might help to understand defence mechanisms against DNA intercalating substances.

\section{Conclusions}

Traditional Chinese and European Medicine comprise promising plants that might be used for antiviral, antitrypanosomal and anticancer therapy. The promising discoveries of highly effective plants against viral hepatitis, trypanosomiasis and liver and intestinal cancer cells, however, require further research to establish new lead structures or their combinations for the treatment of these important traditional diseases.

\section{Financial Support}

This study was supported in part by the Ministerio de Ciencia y Tecnología, Plan Nacional de Investigación Científica, Desarrollo e Innovación Tecnológica (Grant SAF2010-15517), Spain.

\section{References}

1. Jiangsu New Medicine College Editorial Board. A Grand Dictionary of Chinese Medicinal Herbs, 3rd ed.; Shanghai Science Technology Publishing Co.: Shanghai, China, 1995; p. 2754. 
2. Efferth, T.; Herrmann, F.; Tahrani, A.; Wink, M. Cytotoxic activity towards cancer cells of arteanuine B, artemisitene, scopoletin and 1,8-cineole derived from Artemisia annua L. in comparison to artemisinin. Phytomedicine 2011, 18, 959-969.

3. Efferth, T.; Romero, M.R.; Wolf, D.G.; Stamminger, T.; Marin, J.J.; Marschall, M. The antiviral activities of artemisinin and artesunate. Clin. Infect. Dis. 2008, 47, 804-811.

4. Efferth, T.; Li, P.C.; Konkimalla, V.S.; Kaina, B. From traditional Chinese medicine to rational cancer therapy. Trends Mol. Med. 2007, 13, 353-361.

5. Wohlfarth, C.; Efferth, T. Natural products as promising drug candidates for the treatment of hepatitis B and C. Acta Pharmacol. Sin. 2009, 30, 25-30.

6. Romero, M.R.; Serrano, M.A.; Vallejo, M.; Efferth, T.; Alvarez, M.; Marin, J.J. Antiviral effect of artemisinin from Artemisia annua against a model member of the Flaviviridae family, the bovine viral diarrhoea virus (BVDV). Planta Med. 2006, 72, 1169-1174.

7. Romero, M.R.; Efferth, T.; Serrano, M.A.; Castaño, B.; Macias, R.I.; Briz, O.; Marin, J.J. Effect of artemisinin/artesunate as inhibitors of hepatitis B virus production in an "in vitro" replicative system. Antiviral Res. 2005, 68, 75-83.

8. Youns, M.; Hoheisel, J.D.; Efferth, T. Traditional Chinese medicines (TCMs) for molecular targeted therapies of tumours. Curr. Drug. Discov. Technol. 2010, 7, 37-45.

9. Van Wyk, B.E.; Wink, M. Medicinal Plants of the World, 1st ed.; BRIZA: Pretoria, South Africa, 2004.

10. Heinrich, M.; Leonti, M.; Nebel, S.; Peschel, W. "Local Food-Nutraceuticals": An example of a multidisciplinary research project on local knowledge. J. Physiol. Pharmacol. 2005, 56, 5-22.

11. Heinrich, M.; Lee Teoh, H. Galanthamine from snowdrop-The development of a modern drug against Alzheimer's disease from local Caucasian knowledge. J. Ethnopharmacol. 2004, 92, 147-162.

12. Wink, M.; Schimmer, O. Molecular modes of action of defensive secondary metabolites. In Annual Plant Reviews Volume 39: Functions and Biotechnology of Plant Secondary Metabolites, 2ne ed.; Wink, M., Ed.; Wiley-Blackwell: Oxford, UK, 2010; Chapter 2, pp. 21-161.

13. Dr. Duke's Phytochemical and Ethnobotanical Databases. Fulton, Maryland, USA, 2011. Available online: http://www.ars-grin.gov/duke/plants.html (accessed on 05 August 2011).

14. Tanikawa, K. Pathogenesis and treatment of hepatitis $\mathrm{C}$ virus-related liver diseases. Hepatobiliary Pancreat. Dis. Int. 2004, 3, 17-20.

15. Liang, T.J.; Rehermann, B.; Seeff, L.B.; Hoofnagle, J.H. Pathogenesis, natural history, treatment, and prevention of hepatitis C. Ann. Intern. Med. 2000, 132, 296-305.

16. McHutchison, J.G.; Gordon, S.C.; Schiff, E.R.; Shiffman, M.L.; Lee, W.M.; Rustgi, V.K.; Goodman, Z.D.; Ling, M.H.; Cort, S.; Albrecht, J.K. Interferon alfa-2b alone or in combination with ribavirin as initial treatment for chronic hepatitis C. Hepatitis Interventional Therapy Group. N. Engl. J. Med. 1998, 339, 1485-1492.

17. Coon, J.T.; Ernst, E. Complementary and alternative therapies in the treatment of chronic hepatitis C: A systematic review. J. Hepatol. 2004, 40, 491-500.

18. Buckwold, V.E.; Beer, B.E.; Donis, R.O. Bovine viral diarrhea virus as a surrogate model of hepatitis $\mathrm{C}$ virus for the evaluation of antiviral agents. Antivir. Res. 2003, 60, 1-15. 
19. Romero, M.R.; Serrano, M.A.; Efferth, T.; Alvarez, M.; Marin, J.J. Effect of cantharidin, cephalotaxine and homoharringtonine on "in vitro" models of hepatitis B virus (HBV) and bovine viral diarrhoea virus (BVDV) replication. Planta Med. 2007, 73, 552-558.

20. Kim, T.G.; Kang, S.Y.; Jung, K.K.; Kang, J.H.; Lee, E.; Han, H.M.; Kim, S.H. Antiviral activities of extracts isolated from Terminalis chebula Retz., Sanguisorba officinalis L., Rubus coreanus Miq. and Rheum palmatum L. against hepatitis B virus. Phytother. Res. 2001, 15, 718-720.

21. Pang, R.; Tao, J.; Zhang, S.; Zhu, J.; Yue, X.; Zhao, L.; Ye, P.; Zhu, Y. In vitro anti-hepatitis B virus effect of Hypericum perforatum L. J. Huazhong Univ. Sci. Technol. Med. Sci. 2010, 30, 98-102.

22. Li, Z.; Li, L.J.; Sun, Y.; Li, J. Identification of natural compounds with anti-hepatitis B virus activity from Rheum palmatum L. ethanol extract. Chemotherapy 2007, 53, 320-326.

23. Chiang, L.C.; Ng, L.T.; Liu, L.T.; Shieh, D.E.; Lin, C.C. Cytotoxicity and anti-hepatitis B virus activities of saikosaponins from Bupleurum species. Planta Med. 2003, 69, 705-709.

24. Pink, R.; Hudson, A.; Mouriès, M.A.; Bending, M. Opportunities and challenges in antiparasitic drug discovery. Nat. Rev. Drug Discov. 2005, 4, 727-740.

25. Trouiller, P.; Olliaro, P.; Torreele, E.; Orbinski, J.; Laing, R.; Ford, N. Drug development for neglected diseases: A deficient market and a public-health policy failure. Lancet 2002, 359, 2188-2194.

26. Hoet, S.; Opperdoes, F.; Brun, R.; Quetin-Leclerq, J. Natural products active against African trypanosomes: A step towards new drugs. Nat. Prod. Rep. 2004, 21, 353-364.

27. Räz, B.; Iten, M.; Grether-Bühler, Y.; Kaminsky, R.; Brun, R. The Alamar Blue assay to determine drug sensitivity of African trypanosomes (T.b. rhodesiense and T.b. gambiense) in vitro. Acta Trop. 1997, 68, 139-147.

28. Kristjanson, P.M.; Swallow, B.M.; Rowlands, G.J.; Kruska, R.L.; de Leeuw, P.N. Measuring the costs of African animal trypanosomiasis, the potential benefits of control and returns to research. Agric. Syst. 1999, 59, 79-98.

29. Fairlamb, A.H. Chemotherapy of human African trypanosomiasis: Current status and future prospects. Trends Parasitol. 2003, 19, 488-494.

30. Fairlamb, A.H. Target discovery and validation with special reference to trypanothione. In Drugs Against Parasitic Diseases: R\&D Methodologies and Issues, 1st ed.; Fairlamb, A.H., Ridley, R.G., Vial, H.J., Eds.; WHO TDR: Geneva, Switzerland, 2003; pp. 107-118.

31. Croft, S.L. The current status of antiparasitic chemotherapy. Parasitology 1997, Suppl. 114, 3-15.

32. Ross, C.A.; Sutherland, D.V. Drug resistance in trypanosomatids. In Trypanosomiasis and Leishmaniasis: Biology and Control, 1st ed.; Hide, G., Mottram, J.C., Coombs, G.H., Holmes, P.H., Eds.; CAB international: Wallinford, Oxon, 1997; pp. 259-269.

33. Newman, D.J.; Cragg, G.M.; Snader, K.M. Natural products as sources of new drugs over the period 1981-2002. J. Nat. Prod. 2003, 66, 1022-1037.

34. Legros, D.; Ollivier, G.; Gastellu-Etchegorry, M.; Paquet, C.; Burri, C.; Jannin, J.; Büscher, P. Treatment of human African trypanosomiasis-Present situation and needs for research and development. Lancet Infect. Dis. 2002, 2, 437-440.

35. Brun, R.; Schumacher, R.; Schmid, C.; Kunz, C.; Burri, C. The phenomenon of treatment failures in Human African Trypanosomiasis. Trop. Med. Int. Health. 2001, 6, 906-914. 
36. Marin, J.J.; Castaño, B.; Blazquez, A.G.; Rosales, R.; Efferth, T.; Monte, M.J. Strategies for overcoming chemotherapy resistance in enterohepatic tumours. Curr. Mol. Med. 2010, 10, 467-485.

37. Vallejo, M.; Castro, M.A.; Medarde, M.; Macias, R.I.; Romero, M.R.; El-Mir, M.Y.; Monte, M.J.; Briz, O.; Serrano, M.A.; Marin, J.J. Novel bile acid derivatives (BANBs) with cytostatic activity obtained by conjugation of their side chain with nitrogenated bases. Biochem. Pharmacol. 2007, 73, 1394-1404.

38. Baltz, T.; Baltz, D.; Giroud, C.; Crockett, J. Cultivation in a semi-defined medium of animal infective forms of Trypanosoma brucei, T. equiperdum, T. evansi, T. rhodesiense and T. gambiense. EMBO J. 1985, 4, 1273-1277.

39. Kniazeff, A.J.; Wopschall, L.J.; Hopps, H.E.; Morris, C.S. Detection of bovine viruses in fetal bovine serum used in cell culture. In Vitro 1975, 11, 400-403.

40. Mosmann, T. Rapid colorimetric assay for cellular growth and survival: Application to proliferation and cytotoxicity assays. J. Immunol. Methods 1983, 65, 55-63.

41. Korba, B.E.; Gerin, J.L. Use of a standardized cell culture assay to assess activities of nucleoside analogs against hepatitis B virus replication. Antivir. Res. 1992, 19, 55-70.

42. Fautz, R.; Husein, B.; Hechenberger, C. Application of the neutral red assay (NR assay) to monolayer cultures of primary hepatocytes: Rapid colorimetric viability determination for the unscheduled DNA synthesis test (UDS). Mutat. Res. 1991, 253, 173-179.

43. Balasubrahmanyam, A.; Baranwal, V.K.; Lodha, M.L.; Varma, A.; Kapoor, H.C. Purification and properties of growth stage-dependent antiviral proteins from the leaves of Celosia cristata. Plant Sci. 2000, 154, 13-21.

44. Begam, M.; Kumar, S.; Roy, S.; Campanella, J.J.; Kapoor, H.C. Molecular cloning and functional identification of a ribosome inactivating/antiviral protein from leaves of post-flowering stage of Celosia cristata and its expression in E. coli. Phytochemistry 2006, 67, 2441-2449.

45. Begam, M.; Narwal, S.; Roy, S.; Kumar, S.; Lodha, M.L.; Kapoor, H.C. An antiviral protein having deoxyribonuclease and ribonuclease activity from leaves of the post-flowering stage of Celosia cristata. Biochemistry (Mosc). 2006, Suppl. 71, 44-48.

46. Gholizadeh, A.; Kohnehrouz, B.B.; Santha, I.M.; Lodha, M.L.; Kapoor, H.C. Cloning and expression of small cDNA fragment encoding strong antiviral peptide from Celosia cristata in Escherichia coli. Biochemistry (Mosc). 2005, 70, 1005-1010.

47. Gholizadeh, A.; Santha, I.M.; Kohnehrouz, B.B.; Lodha, M.L.; Kapoor, H.C. Cystatins may confer viral resistance in plants by inhibition of a virus-induced cell death phenomenon in which cysteine proteinases are active: Cloning and molecular characterization of a cDNA encoding cysteine-proteinase inhibitor (celostatin) from Celosia cristata (crested cock's comb). Biotechnol. Appl. Biochem. 2005, 42, 197-204.

48. Gholizadeh, A.; Kapoor, H.C. Modifications in the purification protocol of Celosia cristata antiviral proteins lead to protein that can be N-terminally sequenced. Protein Pept. Lett. 2004, 11, 551-561.

49. Baranwal, V.K.; Tumer, N.E.; Kapoor, H.C. Depurination of ribosomal RNA and inhibition of viral RNA translation by an antiviral protein of Celosia cristata. Indian J. Exp. Biol. 2002, 40, 1195-1197. 
50. Lin, Y.L.; Shen, C.C.; Huang, Y.J.; Chang, Y.Y. Homoflavonoids from Ophioglossum Petiolatum. J. Nat. Prod. 2005, 68, 381-384.

51. Hayashi, K.; Kamiya, M.; Hayashi, T. Virucidal effects of the steam distillate from Houttuynia cordata and its components on HSV-1, influenza virus, and HIV. Planta Med. 1995, 61, 237-241.

52. Lin, T.Y.; Liu, Y.C.; Jheng, J.R.; Tsai, H.P.; Jan, J.T.; Wong, W.R.; Horng, J.T. Anti-enterovirus 71 activity screening of chinese herbs with anti-infection and inflammation activities. Am. J. Chin. Med. 2009, 37, 143-158.

53. Lau, K.M.; Lee, K.M.; Koon, C.M.; Cheung, C.S.; Lau, C.P.; Ho, H.M.; Lee, M.Y.; Au, S.W.; Cheng, C.H.; Lau, C.B.; et al. Immunomodulatory and anti-SARS activities of Houttuynia cordata. J. Ethnopharmacol. 2008, 118, 79-85.

54. Ren, X.; Sui, X.; Yin, J. The effect of Houttuynia cordata injection on pseudorabies herpesvirus (PrV) infection in vitro. Pharm. Biol. 2011, 49, 161-166.

55. Chou, S.C.; Su, C.R.; Ku, Y.C.; Wu, T.S. The constituents and their bioactivities of Houttuynia cordata. Chem. Pharm. Bull. (Tokyo). 2009, 57, 1227-1230.

56. Gonzalez, O.; Fontanes, V.; Raychaudhuri, S.; Loo, R.; Loo, J.; Arumugaswami, V.; Sun, R.; Dasgupta, A.; French, S.W. The heat shock protein inhibitor Quercetin attenuates hepatitis C virus production. Hepatology. 2009, 50, 1756-1764.

57. Choi, H.J.; Song, J.H.; Park, K.S.; Kwon, D.H. Inhibitory effects of quercetin 3-rhamnoside on influenza A virus replication. Eur. J. Pharm. Sci. 2009, 37, 329-333.

58. Jung, H.J.; Sung, W.S.; Yeo, S.H.; Kim, H.S.; Lee, I.S.; Woo, E.R.; Lee, D.G. Antifungal effect of amentoflavone derived from Selaginella tamariscina. Arch. Pharm. Res. 2006, 29, 746-751.

59. Lee, J.; Choi, Y.; Woo, E.R.; Lee, D.G. Antibacterial and synergistic activity of isocryptomerin isolated from Selaginella tamariscina. J. Microbiol. Biotechnol. 2009, 19, 204-207.

60. Lee, J.; Choi, Y.; Woo, E.R.; Lee, D.G. Isocryptomerin, a novel membrane-active antifungal compound from Selaginella tamariscina. Biochem. Biophys. Res. Commun. 2009, 379, 676-680.

61. Lee, J.S.; Lee, M.S.; Oh, W.K.; Sul, J.Y. Fatty acid synthase inhibition by amentoflavone induces apoptosis and antiproliferation in human breast cancer cells. Biol. Pharm. Bull. 2009, 32, 1427-1432.

62. Gao, L.L.; Yin, S.L.; Li, Z.L.; Sha, Y.; Pei, Y.H.; Shi, G.; Jing, Y.K.; Hua, H.M. Three novel sterols isolated from Selaginella tamariscina with antiproliferative activity in leukemia cells. Planta Med. 2007, 73, 1112-1115.

63. Lee, C.W.; Choi, H.J.; Kim, H.S.; Kim, D.H.; Chang, I.S.; Moon, H.T.; Lee, S.Y.; Oh, W.K.; Woo, E.R. Biflavonoids isolated from Selaginella tamariscina regulate the expression of matrix metalloproteinase in human skin fibroblasts. Bioorg. Med. Chem. 2008, 16, 732-738.

64. Rao, K.; Ch, B.; Narasu, L.M.; Giri, A. Antibacterial activity of Alpinia galanga (L) Willd crude extracts. Appl. Biochem. Biotechnol. 2010, 162, 871-884.

65. Weerakkody, N.S.; Caffin, N.; Lambert, L.K.; Turner, M.S.; Dykes, G.A. Synergistic antimicrobial activity of galangal (Alpinia galanga), rosemary (Rosmarinus officinalis) and lemon iron bark (Eucalyptus staigerana) extracts. J. Sci. Food Agric. 2011, 91, 461-468.

66. Kaur, A.; Singh, R.; Dey, C.S.; Sharma, S.S.; Bhutani, K.K.; Singh, I.P. Antileishmanial phenylpropanoids from Alpinia galanga (Linn.) Willd. Indian J. Exp. Biol. 2010, 48, 314-317. 
67. Tamura, S.; Shiomi, A.; Kimura, T.; Murakami, N. Halogenated analogs of 1'-acetoxychavicol acetate, Rev-export inhibitor from Alpinia galanga, designed from mechanism of action. Bioorg. Med. Chem. Lett. 2010, 20, 2082-2085.

68. Tamura, S.; Shiomi, A.; Kaneko, M.; Ye, Y.; Yoshida, M.; Yoshikawa, M.; Kimura, T.; Kobayashi, M.; Murakami, N. New Rev-export inhibitor from Alpinia galanga and structure-activity relationship. Bioorg. Med. Chem. Lett. 2009, 19, 2555-2557.

69. Liu, Y.; Murakami, N.; Zhang, S.; Xu, T. Structure-activity relationships of 1'-acetoxychavicol acetate homologues as new nuclear export signal inhibitors. Pharmazie 2007, 62, 659-662.

70. Ye, Y.; Li, B. 1'S-1'-acetoxychavicol acetate isolated from Alpinia galanga inhibits human immunodeficiency virus type 1 replication by blocking Rev transport. J. Gen. Virol. 2006, 87, 2047-2053.

71. Miyazawa, M.; Nakamura, Y.; Ishikawa, Y. Insecticidal diarylheptanoid from Alpinia oxyphylla against larvae of Drosophila melanogaster. Nat. Prod. Lett. 2001, 15, 75-79.

72. Shin, T.Y.; Won, J.H.; Kim, H.M.; Kim, S.H. Effect of Alpinia oxyphylla fruit extract on compound 48/80-induced anaphylactic reactions. Am. J. Chin. Med. 2001, 29, 293-302.

73. He, Z.H.; Ge, W.; Yue, G.G.; Lau, C.B.; He, M.F.; But, P.P. Anti-angiogenic effects of the fruit of Alpinia oxyphylla. J. Ethnopharmacol. 2010, 132, 443-449.

74. Li, G.L.; Zhu, D.Y. Two dichromenes from Evodia lepta. J. Asian Nat. Prod. Res. 1999, 1, 337-341.

75. Fiore, C.; Eisenhut, M.; Krausse, R.; Ragazzi, E.; Pellati, D.; Armanini, D.; Bielenberg, J. Antiviral effects of Glycyrrhiza species. Phytother. Res. 2008, 22, 141-148.

76. Zhang, Y.; Chen, Y.; Fan, C.; Ye, W.; Luo, J. Two new iridoid glucosides from Hedyotis diffusa. Fitoterapia 2010, 81, 515-517.

77. Li, C.; Xue, X.; Zhou, D.; Zhang, F.; Xu, Q.; Ren, L.; Liang, X. Analysis of iridoid glucosides in Hedyotis diffusa by high-performance liquid chromatography/electrospray ionization tandem mass spectrometry. J. Pharm. Biomed. Anal. 2008, 48, 205-211.

78. Lin, C.C.; Ng, L.T.; Yang, J.J.; Hsu, Y.F. Anti-inflammatory and hepatoprotective activity of peh-hue-juwa-chi-cao in male rats. Am. J. Chin. Med. 2002, 30, 225-234.

79. Jiang, R.W.; Zhou, J.R.; Hon, P.M.; Li, S.L.; Zhou, Y.; Li, L.L.; Ye, W.C.; Xu, H.X.; Shaw, P.C.; But, P.P. Lignans from Dysosma versipellis with inhibitory effects on prostate cancer cell lines. J. Nat. Prod. 2007, 70, 283-286.

80. Mulyaningsih, S.; Youns, M.; El-Readi, M.Z.; Ashour, M.L.; Nibret, E.; Sporer, F.; Herrmann, F.; Reichling, J.; Wink, M. Biological activity of the essential oil of Kadsura longipedunculata (Schisandraceae) and its major components. J. Pharm. Pharmacol. 2010, 62, 1037-1044.

81. Kim, H.J.; Chang, E.J.; Cho, S.H.; Chung, S.K.; Park, H.D.; Choi, S.W. Antioxidative activity of resveratrol and its derivatives isolated from seeds of Paeonia lactiflora. Biosci. Biotechnol. Biochem. 2002, 66, 1990-1993.

82. Fuggetta, M.P.; D’Atri, S.; Lanzilli, G.; Tricarico, M.; Cannavò, E.; Zambruno, G.; Falchetti, R.; Ravagnan, G. In vitro antitumour activity of resveratrol in human melanoma cells sensitive or resistant to temozolomide. Melanoma Res. 2004, 14, 189-196.

83. Kang, J.H.; Park, Y.H.; Choi, S.W.; Yang, E.K.; Lee, W.J. Resveratrol derivatives potently induce apoptosis in human promyelocytic leukemia cells. Exp. Mol. Med. 2003, 35, 467-474. 
84. Kim, H.J.; Chang, E.J.; Bae, S.J.; Shim, S.M.; Park, H.D.; Rhee, C.H.; Park, J.H.; Choi, S.W. Cytotoxic and antimutagenic stilbenes from seeds of Paeonia lactiflora. Arch. Pharm. Res. 2002, 25, 293-299.

85. Loizzo, M.R.; Tundis, R.; Menichini, F.; Saab, A.M.; Statti, G.A.; Menichini, F. Antiproliferative effects of essential oils and their major constituents in human renal adenocarcinoma and amelanotic melanoma cells. Cell Prolif. 2008, 41, 1002-1012.

86. Yang, L.Q.; Singh, M.; Yap, E.H.; Ng, G.C.; Xu, H.X.; Sim, K.Y. In vitro response of Blastocystis hominis against traditional Chinese medicine. J. Ethnopharmacol. 1996, 55, 35-42.

87. Hirano, H.; Osawa, E.; Yamaoka, Y.; Yokoi, T. Gastric-mucous membrane protection activity of coptisine derivatives. Biol. Pharm. Bull. 2001, 24, 1277-1281.

88. Joshi, P.V.; Shirkhedkar, A.A.; Prakash, K.; Maheshwari, V.L. Antidiarrheal activity, chemical and toxicity profile of Berberis aristata. Pharm. Biol. 2011, in press.

89. Liu, X.; Li, G.; Zhu, H.; Huang, L.; Liu, Y.; Ma, C.; Qin, C. Beneficial effect of berberine on hepatic insulin resistance in diabetic hamsters possibly involves in SREBPs, LXRalpha and PPARalpha transcriptional programs. Endocr. J. 2011, in press.

90. Dvorak, Z. Berberine: A multipotent remedy with unknown cellular target? Poult. Sci. 2010, 89, 1787.

91. Patil, J.B.; Kim, J.; Jayaprakasha, G.K. Berberine induces apoptosis in breast cancer cells (MCF-7) through mitochondrial-dependent pathway. Eur. J. Pharmacol. 2010, 645, 70-78.

92. Lin, C.C.; Ng, L.T.; Hsu, F.F.; Shieh, D.E.; Chiang, L.C. Cytotoxic effects of Coptis chinensis and Epimedium sagittatum extracts and their major constituents (berberine, coptisine and icariin) on hepatoma and leukaemia cell growth. Clin. Exp. Pharmacol. Physiol. 2004, 31, 65-69.

93. Miyazawa, M.; Nakamura, Y.; Ishikawa, Y. Insecticidal sesquiterpene from Alpinia oxyphylla against Drosophila melanogaster. J. Agric. Food Chem. 2000, 48, 3639-3641.

94. Pu, J.X.; Gao, X.M.; Lei, C.; Xiao, W.L.; Wang, R.R.; Yang, L.B.; Zhao, Y.; Li, L.M.; Huang, S.X.; Zheng, Y.T.; Sun, H.D. Three new compounds from Kadsura longipedunculata. Chem. Pharm. Bull. (Tokyo). 2008, 56, 1143-1146.

95. Kamath, S.; Skeels, M.; Pai, A. Significant differences in alkaloid content of Coptis chinensis (Huanglian), from its related American species. Chin. Med. 2009, 4, doi:10.1186/1749-8546-4-17.

96. Rosenkranz, V.; Wink, M. Alkaloids induce programmed cell death in bloodstream forms of trypanosomes (Trypanosoma b. brucei). Molecules 2008, 13, 2462-2473.

97. Merschjohann, K.; Sporer, F.; Steverding, D.; Wink, M. In vitro effect of alkaloids on bloodstream forms of Trypanosoma brucei and T. congolense. Planta Med. 2001, 67, 623-627.

98. Rosenkranz, V.; Wink, M. Alkaloids induce programmed cell death in bloodstream forms of trypanosomes (Trypanosoma b. brucei). Molecules. 2008, 13, 2462-2473.

99. Freiburghaus, F.; Kaminsky, R.; Nkunya, M.H.H.; Brun, R. Evaluation of African medicinal plants for their in vitro trypanocidal activity. J. Ethnopharmacol. 1996, 55, 1-11. 


\section{Appendix}

Origin and current area of use of the medicinal plants included in our study.

\begin{tabular}{|c|c|c|c|}
\hline Family & Species & Origin & Area of Use \\
\hline Acanthaceae & Andrographis paniculata & India & $\begin{array}{l}\text { India, Sri Lanka, SE Asia, East } \\
\text { Asia }\end{array}$ \\
\hline Amaranthaceae & Celosia cristata & Tropical Asia & $\begin{array}{l}\text { India, SE Asia, China, Africa, } \\
\text { South America }\end{array}$ \\
\hline \multirow{5}{*}{ Apiaceae } & Bupleurum chinense & China & East Asia, China \\
\hline & Bupleurum marginatum & China & East Asia, China \\
\hline & Centella asiatica & $\begin{array}{l}\text { East Asia, India, Sri Lanka, } \\
\text { northern Australia, Iran, } \\
\text { Melanesia, Papua New Guinea }\end{array}$ & $\begin{array}{l}\text { East Asia, India, Sri Lanka, } \\
\text { Australia, Melanesia, Papua New } \\
\text { Guinea, Middle East, Africa }\end{array}$ \\
\hline & Cnidium monnieri & China & East Asia, China \\
\hline & Saposhnikovia divaricata & Central Asia (steppe region) & Central Asia, East Asia, China \\
\hline \multirow[t]{4}{*}{ Araliaceae } & Eleutherococcus senticosus & Siberia & Siberia, China, Korea, Japan \\
\hline & Panax ginseng China & China & Siberia, China, Korea, Japan \\
\hline & Panax ginseng Korea & Korea & Siberia, China, Korea, Japan \\
\hline & Panax notoginseng & China & Siberia, China, Korea, Japan \\
\hline Arecaceae & Areca catechu & Malaysia, Philipines & $\begin{array}{l}\text { SE Asia, East Asia, India, Sri } \\
\text { Lanka, Papua New Guinea }\end{array}$ \\
\hline Asclepiadaceae & Cynanchum paniculatum & SE Asia & East Asia, SE Asia \\
\hline \multirow[t]{10}{*}{ Asteraceae } & Artemisia annua & Asia, introduced worldwide & worldwide \\
\hline & Artemisia capillaris & Asia & Asia \\
\hline & Arctium lappa & $\begin{array}{l}\text { Northern Hemisphere (Europe, } \\
\text { Asia, North America) }\end{array}$ & Europe, Asia \\
\hline & Centipeda minima & Asia, Himalaya & Asia \\
\hline & Chrysanthemum indicum & India & Asia \\
\hline & Chrysanthemum morifolium & Asia & Asia \\
\hline & Eclipta prostrata & Tropical Asia, South America & $\begin{array}{l}\text { Tropical Asia, East Asia, South } \\
\text { America }\end{array}$ \\
\hline & Senecio scandens & Asia & Asia \\
\hline & Siegesbeckia orientalis & Tropical Asia & Tropical Asia, East Asia, Africa \\
\hline & Taraxacum officinale & $\begin{array}{l}\text { Northern Hemisphere (Europe, } \\
\text { Asia, North America) }\end{array}$ & Europe, Asia, North America \\
\hline \multirow[t]{3}{*}{ Berberidaceae } & Berberis bealei & $\begin{array}{l}\text { Asia, introduced in America, } \\
\text { Europe }\end{array}$ & Asia, America, Europe \\
\hline & Dysosma versipellis & East Asia & East Asia, China \\
\hline & Epimedium koreanum & East Asia (Korea) & East Asia, China \\
\hline \multirow[t]{3}{*}{ Brassicaceae } & Capsella bursa-pastoris & $\begin{array}{l}\text { Northern Hemisphere (Europe, } \\
\text { Asia, North America) }\end{array}$ & Europe, Asia \\
\hline & Isatis indigotica (root) & Central Asia (steppe region) & Central Asia, East Asia, China \\
\hline & Isatis indigotica (leaf) & Central Asia (steppe region) & Central Asia, East Asia, China \\
\hline Caprifoliaceae & Lonicera confusa & East Asia & East Asia, China \\
\hline Convallariaceae & Polygonatum kingianum & Asia & Asia \\
\hline Crassulaceae & Rhodiola rosea & $\begin{array}{l}\text { Northern Hemisphere (Europe, } \\
\text { Asia, North America) }\end{array}$ & Europe, Asia, North America \\
\hline Cupressaceae & Platycladus orientalis & $\begin{array}{l}\text { China, introduced in most of } \\
\text { Asia }\end{array}$ & Asia \\
\hline
\end{tabular}


Appendix. Cont.

\begin{tabular}{|c|c|c|c|}
\hline Family & Species & Origin & Area of Use \\
\hline Dryopteridaceae & Cyrtomium fortunei & $\begin{array}{l}\text { Asia, introduced in America, } \\
\text { Europe }\end{array}$ & Asia \\
\hline Ephedraceae & Ephedra sinica & China & East Asia \\
\hline Equisetaceae & Equisetum hiemale & $\begin{array}{l}\text { Northern Hemisphere (Europe, } \\
\text { Asia, North America) }\end{array}$ & Europe, Asia, North America \\
\hline Euphorbiaceae & Croton tiglium & SE Asia & East Asia, SE Asia \\
\hline \multirow[t]{7}{*}{ Fabaceae } & Abrus cantoniensis & Southern China & East Asia, SE Asia \\
\hline & Acacia catechu & East Asia, SE Asia & East Asia, SE Asia \\
\hline & Cassia tora & $\begin{array}{l}\text { East Asia, SE Asia, introduced } \\
\text { to Middle and South America, } \\
\text { Africa, Middle East }\end{array}$ & Europe, Asia, America, Africa \\
\hline & Desmodium styracifolium & SE Asia & East Asia, SE Asia \\
\hline & Glycyrrhiza inflata & Central Asia (Mongolia, China) & East Asia, Central Asia \\
\hline & Spatholobus suberectus & Tropical Asia & India, East Asia, SE Asia \\
\hline & Sutherlandia frutescens & South Africa & South Africa, Europe \\
\hline \multirow[t]{2}{*}{ Geraniaceae } & Geranium wilfordii & East Asia & East Asia, China \\
\hline & Pelargonium sidoides & South Africa & South Africa, Europe \\
\hline Ginkgoaceae & Ginkgo biloba & China & Asia, Europe, North America \\
\hline Hypericaceae & Hypericum japonicum & Japan & East Asia, China \\
\hline Iridaceae & Belamcanda chinensis & China & East Asia, China \\
\hline \multirow[t]{3}{*}{ Lamiaceae } & Mentha haplocalyx & China & East Asia, China \\
\hline & Prunella vulgaris & $\begin{array}{l}\text { Northern Hemisphere (Europe, } \\
\text { Asia, North America) }\end{array}$ & Europe, Asia, North America \\
\hline & Scutellaria baicalensis & $\begin{array}{l}\text { Central Asia (Russia, } \\
\text { Mongolia, China) }\end{array}$ & East Asia, Central Asia \\
\hline Lauraceae & Cinnamomum cassia & $\begin{array}{l}\text { Tropical Asia (India, East } \\
\text { Asia, SE Asia) }\end{array}$ & India, East Asia, SE Asia \\
\hline Loranthaceae & Taxillus chinensis & China & East Asia, China \\
\hline Lythraceae & Punica granatum & Middle East, Himalaya & Europe, Asia, America, Africa \\
\hline Magnoliaceae & Magnolia officinalis & Himalaya, China & East Asia, China \\
\hline Melanthiaceae & Paris polyphylla & Himalaya, China & East Asia, China \\
\hline Myrsinaceae & Lysimachia christinae & China & East Asia, China \\
\hline Myrtaceae & Eucalyptus robusta & East Australia & $\begin{array}{l}\text { Europe, Asia, America, Africa, } \\
\text { Australia }\end{array}$ \\
\hline Ophioglossaceae & Ophioglossum vulgatum & $\begin{array}{l}\text { Northern Hemisphere (Europe, } \\
\text { Asia, North America) }\end{array}$ & Europe, Asia, North America \\
\hline Orchidaceae & Dendrobium loddigesii & SE Asia & East Asia, SE Asia \\
\hline Paeoniaceae & Paeonia lactiflora & China & East Asia \\
\hline Pedaliaceae & Harpagophytum procumbens & South Africa & South Africa, Europe \\
\hline Poaceae & Cymbopogon distans & Himalaya, China & East Asia, China \\
\hline \multirow[t]{4}{*}{ Polygonaceae } & $\begin{array}{l}\text { Fallopia japonica (syn. } \\
\text { Polygonum cuspidatum) }\end{array}$ & East Asia & East Asia, China \\
\hline & $\begin{array}{l}\text { Fallopia multiflora (syn. } \\
\text { Polygonum multiflorum) }\end{array}$ & East Asia & East Asia, China \\
\hline & Polygonum aviculare & $\begin{array}{l}\text { Northern Hemisphere (Europe, } \\
\text { Asia, North America) }\end{array}$ & Europe, Asia, North America \\
\hline & Rheum officinale & Asia & Europe, Asia, North America \\
\hline
\end{tabular}


Appendix. Cont.

\begin{tabular}{llll}
\hline \multicolumn{1}{c}{ Family } & \multicolumn{1}{c}{ Species } & \multicolumn{1}{c}{ Origin } & \multicolumn{1}{c}{ Area of Use } \\
\hline Ranunculaceae & Coptis chinensis & China & East Asia, China \\
\hline Rosaceae & Rosa chinensis & China & East Asia, China \\
& Rosa laevigata & Se Asia, China & Europe, Asia, North America \\
& Sanguisorba officinalis & Asia, North America) & Europe, Asia, North America \\
\hline Rubiaceae & Hedyotis diffusa & East Asia & East Asia, China \\
\hline Rutaceae & Evodia lepta & East Asia & East Asia, China \\
& Evodia rutaecarpa & East Asia & East Asia, China \\
& Phellodendron chinense & Himalaya, China & East Asia, China \\
\hline Saururaceae & Houttuynia cordata & East Asia, SE Asia & East Asia, SE Asia \\
\hline Schisandraceae & Kadsura longipedunculata & East Asia & East Asia, China \\
\hline Selaginellaceae & Selaginella tamariscina & East Asia & East Asia, China \\
\hline Valerianaceae & Patrinia scabiosaefolia & East Asia & East Asia, China \\
\hline Verbenaceae & Verbena officinalis & Europe & Europe, Asia, North America \\
\hline Violaceae & Viola yezoensis & East Asia & East Asia, China \\
\hline Zingiberaceae & Alpinia galanga & SE Asia & East Asia, SE Asia \\
& Alpinia oxyphylla & SE Asia & East Asia, SE Asia \\
\hline
\end{tabular}

(C) 2011 by the authors; licensee MDPI, Basel, Switzerland. This article is an open access article distributed under the terms and conditions of the Creative Commons Attribution license (http://creativecommons.org/licenses/by/3.0/). 